\title{
A Role for p38 Mitogen-Activated Protein Kinase in the Regulation of the Serotonin Transporter: Evidence for Distinct Cellular Mechanisms Involved in Transporter Surface Expression
}

\author{
Devadoss J. Samuvel, ${ }^{1}$ Lankupalle D. Jayanthi, ${ }^{1}$ Narayan R. Bhat, ${ }^{2}$ and Sammanda Ramamoorthy ${ }^{1}$ \\ Departments of ${ }^{1}$ Physiology and Neuroscience and ${ }^{~}$ Neurology, Medical University of South Carolina, Charleston, South Carolina 29425
}

The serotonin transporter (SERT) is regulated by various signaling mechanisms that may operate to maintain appropriate levels of synaptic serotonin (5-HT). We demonstrate that one of the mitogen-activated protein kinases (MAPKs), p38 MAPK, regulates SERT. Treatment of rat midbrain synaptosomes with p38 MAPK-specific inhibitors, PD169316 [4-(4-fluorophenyl)-2-(4-nitrophenyl)-5-(4pyridyl)-1H-imidazole] or SB203580 [4-(4-fluorophenyl)-2-(4-methylsulfinylphenyl)-5-(4-pyridyl)-1H-imidazole], reduced 5-HT uptake. An additive SERT inhibition by PD169316 and $\beta$-phorbol 12-myristate 13-acetate ( $\beta$-PMA) indicated the involvement of a protein kinase C (PKC)-independent MAPK pathway. Kinetic studies indicated a significant decrease in the transport capacity $\left(V_{\text {max }}\right)$ after PD169316 treatment of synaptosomes. Biotinylation studies showed reduced SERT proteins in the plasma membrane of synaptosomes after 38 MAPK inhibition and PKC activation. Phosphorylation studies using synaptosomes revealed decreased SERT phosphorylation by PD169316 but increased phosphorylation by $\beta$-PMA. D-Amphetamine enhanced SERT basal phosphorylation and PD169316 blocked this effect. SERT interaction with protein phosphatase $2 \mathrm{~A}$ catalytic subunit and syntaxin 1A decreased after PD169316 or $\beta$-PMA treatment of synaptosomes. In synaptosomes, PKC activation but not p38 MAPK inhibition resulted in SERT redistribution from cholesterolrich lipid raft fractions to nonlipid raft fractions. The presence of phospho-p38 MAPK in synaptosomes and human embryonic kidney 293 (HEK-293) cells suggested the presence of constitutively active p38 MAPK in these preparations. Cotransfection of HEK-293 cells with SERT and a constitutively active form of MAP kinase kinase $3 \mathrm{~b}(\mathrm{E})$ [MKK3b(E)] increased 5-HT transport, and RNA interference targeted to $\mathrm{p} 38$ MAPK inhibited 5-HT uptake, confirming the involvement of active p38 MAPK in SERT expression. Although PD169316 inhibited SERT insertion to the plasma membrane, $\beta$-PMA increased SERT internalization in HEK-293 cells. Together, these results indicate a distinct role of $\mathrm{p} 38$ MAPK in SERT regulation.

Key words: neurotransmitter; phosphorylation; presynaptic; uptake; trafficking; lipid rafts

\section{Introduction}

Serotonin (5-HT) plays an important role in various behavioral and physiological functions (Fozzard, 1989; Jacobs and Azmitia, 1992). The uptake of synaptic 5-HT through $\mathrm{Na}^{+} / \mathrm{Cl}^{-}$dependent serotonin transporter (SERT) is the principal process of terminating serotonergic neurotransmission (Barker and Blakely, 1995; Povlock and Amara, 1997). Altered SERT expression and two polymorphic regions in SERT promoter have been implicated in various types of psychopathology (Montgomery, 1995; Blakely et al., 1997; Murphy et al., 2001). SERT is one of the primary targets for tricyclic antidepressants, serotonin-selective reuptake inhibitors, and drugs of abuse (Rudnick and Wall, 1992; Barker and Blakely, 1995).

Received May 26, 2004; revised Nov. 4, 2004; accepted Nov. 12, 2004

This work was supported by National Institutes of Health Grant MH62612 (S.R.). We thank Dr. John Woodward (Medical University of South Carolina, Charleston, SC) for critical review of and helpful comments on this manuscript.

Correspondence should be addressed to Sammanda Ramamoorthy, Department of Physiology and Neuroscience, Medical University of South Carolina, Charleston, SC 29425. E-mail: rama@musc.edu. DOI:10.1523/JNEUROSCI.3754-04.2005

Copyright $\odot 2005$ Society for Neuroscience $\quad$ 0270-6474/05/250029-13\$15.00/0
5-HT clearance is a highly orchestrated process involving regulation of SERT gene transcription-translation (Lesch et al., 1993; Ramamoorthy et al., 1993a, 1995a,b; Neumaier et al., 1996; Morikawa et al., 1998; Benmansour et al., 1999; Mossner et al., 2001) and posttranslational modification of the transporter (Jayanthi et al., 1994; Miller and Hoffman, 1994; Qian et al., 1997; Ramamoorthy, 2002). The activation of protein kinase C (PKC) and/or inhibition of protein phosphatase regulate SERT (Ramamoorthy et al., 1998a; Bauman et al., 2000). SERT activity attenuates the PKC-mediated SERT phosphorylation and surface expression (Ramamoorthy and Blakely, 1999). SERT also exists in phosphorylated form under basal conditions, although the endogenous kinase(s) linked to basal SERT phosphorylation is currently unknown (Ramamoorthy et al., 1998a).

Mitogen-activated protein kinases (MAPKs) are a family of serine-threonine protein kinases that mediate various biological activities and regulate gene expression in response to various biologic stimuli (Treisman, 1996; Schramm and Limbird, 1999; Tibbles and Woodgett, 1999; McDuffie et al., 2000). MAPKs include the extracellular signal-regulated kinases [(ERKs) 1/2], the 
c-Jun N-terminal kinases [(JNKs) 1/2/3], and p38 MAPKs. p38 MAPKs are activated by various environmental stress and proinflammatory signals (cytokines) linked to both PKC-dependent and independent mechanisms (Tibbles and Woodgett, 1999).

Stress and cytokines also influence 5-HT homeostasis and SERT expression (Chaouloff et al., 1999; Vollmayr et al., 2000; Armando et al., 2003). Because several G-protein-coupled receptors (GPCRs), including 5-HT receptors, activate MAPKs, we explored the idea that SERT activity may be influenced by MAPKs. We describe studies detailing distinct mechanisms by which p38 MAPKs regulate SERT function. Using purified rat midbrain synaptosomes, we demonstrate the effects of p38 MAPK inhibition on SERT function, plasma membrane distribution, and phosphorylation. Because PKC activation results in SERT inhibition that parallels with decreased surface expression and increased phosphorylation, we tested whether p38 MAPK is involved in SERT regulation downstream of PKC activation. Although we demonstrate decreased plasma membrane insertion of SERT after p38 MAPK inhibition, increased SERT endocytosis accounts for the reduction of cell-surface SERT after PKC activation. Furthermore, PKC activation increases SERT basal phosphorylation, and p38 MAPK inhibition decreases SERT basal phosphorylation. We confirm the involvement of p38 MAPK in SERT regulation by cotransfection studies using constitutively active MAP kinase kinase $3 \mathrm{~b}(\mathrm{E})$ [MKK3b(E)] into human embryonic kidney 293 (HEK-293) cells and by RNA interference. Based on our results, we conclude that p38 MAPK-mediated SERT regulation may represent one of the mechanisms involved in maintaining normal-basal expression of SERT.

\section{Materials and Methods}

Materials. $\beta$-Phorbol 12-myristate 13 -acetate ( $\beta$-PMA), bisindolylmaleimide (BIM) I, staurosporine, 5-HT, D-amphetamine, fluoxetine, detergents, horseradish peroxidase-coupled cholera-toxin B-subunit (CTXB), and anti-syntaxin 1A were obtained from Sigma (St. Louis, MO). All cell culture media, Lipofectamine 2000, and other reagents were purchased from Invitrogen (Carlsbad, CA). 5-Hydroxy- $\left[{ }^{3} \mathrm{H}\right]$ tryptamine trifluoroacetate $\left(\left[{ }^{3} \mathrm{H}\right] 5-\mathrm{HT}\right),{ }^{32} \mathrm{PO}_{4}$ carrier-free orthophosphate, protein A-Sepharose beads, ECL reagents, and ECL enhanced film were obtained from Amersham Biosciences (Piscataway, NJ). Sulfosuccinimidyl-2(biotinamido)ethyl-1,3-dithiopropionate (NHS-SS)-biotin and monomeric avidin beads were from Pierce (Rockford, IL). HRP-conjugated secondary antibodies were obtained from Jackson ImmunoResearch Laboratories (West Grove, PA). 2-(2-Amino-3-methyoxyphenyl)-4H-1benzopyran-4-one (PD98059), 4-(4-fluorophenyl)-2-(4-nitrophenyl)-5-(4pyridyl)-1H-imidazole (PD169316), 1,4-diamino-2,3-dicyano-1,4-bis (o-aminophenylmercapto) butadiene (U0126), 4-(4-fluorophenyl)-2(4-methylsulfinylphenyl)-5-(4-pyridyl)imidazole (SB203580), and anthra 1 1,9-cd]pyrazol-6(2H)-one (SP600125) were obtained from Calbiochem (La Jolla, CA). Anti-phosphospecific p38 MAPK (Tyr-182) and antiphospho-mitogen-activated protein kinase-activated protein kinase (MAPKAPK)-2 were purchased from Cell Signaling (Beverly, MA). Antibody to total p38 MAPK was from Santa Cruz Biotechnology (Santa Cruz, CA). siRNA SMART pool for p38 MAPK and scrambled siRNAs were purchased from Upstate (Charlottesville, VA). Anti-calnexin was from Stressgen (Victoria, British Columbia, Canada). Antibodies to caveolin 1, Na/K ATPase, and PP2Ac were from BD Biosciences (San Diego, CA). Mouse anti-TfR antibody was from Zymed Laboratories (South San Francisco, CA). Other reagents were of the highest grade possible from standard sources.

Synaptosome preparations. All animal procedures were in accordance with the National Institutes of Health Guide for the Care and Use of Laboratory Animals, and all animal use protocols were approved by the Institutional Animal Care and Use Committee. Male Sprague Dawley rats $(100-150 \mathrm{gm})$ were decapitated, and the brains were collected in ice-cooled dishes. The midbrain was rapidly dissected and collected in 10 vol (w/v) of cold $0.32 \mathrm{~m}$ sucrose. The tissue was immediately homogenized using a Teflon-glass homogenizer under chilled water and centrifuged at $1000 \times g$ for $15 \mathrm{~min}$ at $4^{\circ} \mathrm{C}$. The resulting supernatant was centrifuged at $15,000 \times g$ for $20 \mathrm{~min}$, and the pellet was washed by resuspending in $0.32 \mathrm{~m}$ sucrose. The washed crude synaptosomal pellet was further purified as described previously (Eichberg et al., 1964; Geerlings et al., 2001). Briefly, crude synaptosomal fractions (3 ml) were layered on top of sucrose gradients prepared with $3 \mathrm{ml}$ each of $0.85,1.0$, and $1.2 \mathrm{~m}$ sucrose (top to bottom) in Beckman SW41 ultracentrifuge tubes. After centrifugation at $85,000 \times g$ for $2 \mathrm{hr}$ at $4^{\circ} \mathrm{C}$, pure synaptosomes that fractionate at the interface of 1.0 and $1.2 \mathrm{~m}$ sucrose were collected and washed once with $0.32 \mathrm{M}$ sucrose. The purified synaptosomes were suspended in regular Krebs'-Ringer's-HEPES (KRH) buffer saturated with $95 \% \mathrm{O}_{2} / 5 \% \mathrm{CO}_{2}$. In experiments testing the role of $\mathrm{Ca}^{2+}$, synaptosomes were suspended in modified Krebs'-bicarbonate buffer containing (in mM): $25 \mathrm{Na}_{2} \mathrm{HCO}_{3}, 124 \mathrm{NaCl}, 5 \mathrm{KCl}, 5 \mathrm{MgSO}_{4}, 10$ glucose, $\mathrm{pH} 7.3$, containing $2 \mathrm{~mm}$ EGTA/0.1 mм EDTA for $15 \mathrm{~min}$ at $30^{\circ} \mathrm{C}$ followed by washing with the same buffer. The resulting pellet was resuspended in modified Krebs'-bicarbonate buffer with or with out $1.5 \mathrm{~mm}$ $\mathrm{CaCl}_{2}$. The replacements in the buffer were adjusted with isotonic concentrations of $\mathrm{N}$-methyl D-glucamine at equivalent molarity. Protein concentration was determined by DC protein assay (Bio-Rad, Hercules, CA) using bovine serum albumin as standard. The purified synaptosomal preparation was used immediately for experiments.

5-HT uptake in synaptosomes. 5-HT uptake was performed as described previously (Ansah et al., 2003). Briefly, $50 \mu \mathrm{g}$ of purified synaptosomes was incubated in $250 \mu \mathrm{l}$ of $\mathrm{KRH}$ buffer, $\mathrm{pH}$ 7.4, containing (in mM): $120 \mathrm{NaCl}, 4.7 \mathrm{KCl}, 2.2 \mathrm{CaCl}_{2}, 10 \mathrm{HEPES}, 1.2 \mathrm{MgSO}_{4}, 1.2 \mathrm{KH}_{2} \mathrm{PO}_{4}$, 5 Tris, and $10 \mathrm{D}$-glucose, containing $0.1 \mathrm{~mm}$ ascorbic acid, $0.1 \mathrm{~mm}$ pargyline, and $20 \mathrm{~nm}\left[{ }^{3} \mathrm{H}\right] 5-\mathrm{HT}$ for $3 \mathrm{~min}$. Synaptosomes were preincubated with the modulators at $37^{\circ} \mathrm{C}$ for the indicated times followed by the addition of $\left[{ }^{3} \mathrm{H}\right] 5-\mathrm{HT}$ to initiate 5 -HT uptake. For saturation analysis, $\left[{ }^{3} \mathrm{H}\right] 5$-HT was mixed with unlabeled 5-HT from $10 \mathrm{~nm}$ to $1 \mu \mathrm{M}$. Nonspecific $\left[{ }^{3} \mathrm{H}\right] 5-\mathrm{HT}$ uptake was defined as the accumulation in the presence of $0.1 \mu \mathrm{M}$ fluoxetine and was subtracted from total uptake. Uptake was terminated with the addition of $3 \mathrm{ml}$ of ice-cold PBS followed by rapid filtration over $0.3 \%$ polyethylenimine-coated glass fiber filters-B on a Brandel Cell Harvester. Filters were washed rapidly with $5 \mathrm{ml}$ of cold PBS, and radioactivity bound to filter was counted by liquid scintillation counter. All uptake assays were performed in triplicate, and mean values of specific uptake \pm SEM of at least three separate experiments were determined.

Immunoprecipitations and immunoblotting. SERT immunoprecipitations and immunoblotting were performed from detergent extracts of synaptosomes as described previously (Ramamoorthy and Blakely, 1999; Bauman et al., 2000). Protein samples were subjected to $4-15 \%$ linear gradient SDS-PAGE, blotted to polyvinylidene difluoride membrane, and probed with specific antibodies as indicated in figures and legends. Immunoreactive bands were visualized by chemiluminescence (ECL reagent). Multiple exposures of blots were obtained to ensure the development within the linear range of the film. Band intensities were quantified using NIH Image (version 1.6).

Surface biotinylation. Purified synaptosomes $(100 \mu \mathrm{g})$ were incubated with $\beta$-PMA, PD169316, and/or vehicle for $30 \mathrm{~min}$ at $37^{\circ} \mathrm{C}$. The samples were washed quickly by centrifugation, and the pellets were treated with NHS-SS-biotin ( $1 \mathrm{mg} / 1 \mathrm{mg}$ protein) for $30 \mathrm{~min}$ at $4^{\circ} \mathrm{C}$ in cold Krebs'bicarbonate buffer. Subsequently, the samples were washed with the same buffer containing $100 \mathrm{~mm}$ glycine, and the pellet was resuspended in radioimmunoprecipitation assay (RIPA) lysis buffer $(10 \mathrm{~mm}$ Tris- $\mathrm{HCl}$, pH 7.5, $150 \mathrm{~mm} \mathrm{NaCl}, 1$ mm EDTA, 1\% Triton X-100, 0.1\% SDS, and 1\% sodium deoxycholate) supplemented with protease inhibitors $(1 \mu \mathrm{g} / \mathrm{ml}$ aprotinin, $1 \mu \mathrm{g} / \mathrm{ml}$ leupeptin, $1 \mu \mathrm{M}$ pepstatin, and $250 \mu \mathrm{M}$ phenylmethylsulfonyl fluoride) and phosphatase inhibitors (10 mm sodium fluoride, $50 \mathrm{~mm}$ sodium pyrophosphate, $5 \mathrm{~mm}$ sodium orthovanadate, and $1 \mu \mathrm{M}$ okadaic acid). The resuspended synaptosomes were triturated 10 times through a 25 gauge needle and centrifuged at $40,000 \times g$ for $20 \mathrm{~min}$. The biotinylated proteins were separated from clear solubilizate by incubating with monomeric avidin beads for $4 \mathrm{hr}$ at $4^{\circ} \mathrm{C}$. Beads were washed three times with RIPA buffer, and bound biotinylated proteins were 
eluted with Laemmli sample buffer (62.5 mm Tris- $\mathrm{HCl}$, pH 6.8. 20\% glycerol, $2 \%$ SDS, and $15 \mu \mathrm{g} / \mathrm{ml}$ dithiothreitol) for $20 \mathrm{~min}$ at $22^{\circ} \mathrm{C}$. Aliquots from total extracts $(50 \mu \mathrm{l})$, unbound fractions $(50 \mu \mathrm{l})$, and entire eluted fractions were separated by SDS-PAGE (10\%), transferred to membrane, and probed with SERT-specific SR-12 antibody. SERT band densities were quantified by scanning and analyzed using NIH Image software. Subsequently, the blots were stripped and reprobed with anticalnexin antibodies to validate the surface biotinylation on plasma membrane proteins. SERT densities from total, nonbiotinylated (represents intracellular pool), and biotinylated (represents surface pool) fractions were normalized using levels of calnexin in total extract to preclude errors accompanying sample loading-transfer, and values were averaged across three experiments as described previously (Qian et al., 1997; Ramamoorthy et al., 1998b; Jayanthi et al., 2004).

SERT phosphorylation. Synaptosomes were incubated with $5.0 \mathrm{mCi}$ of ${ }^{32} \mathrm{PO}_{4}$ carrier-free orthophosphate per milligram of protein for $30 \mathrm{~min}$ before the addition of modulators, as indicated, with continuous shaking at $37^{\circ} \mathrm{C}$ for $30 \mathrm{~min}$ (Vaughan et al., 1997). Each assay contained $500 \mu \mathrm{g}$ of purified synaptosomes. At the end of the incubation, samples were centrifuged, and the pellet was resuspended in RIPA buffer containing protease and phosphatase inhibitors (composition as given above) by passing 10 times through a 25 gauge needle. The clear supernatant obtained after centrifuging the solubilized synaptosomes at $45,000 \times g$ for $40 \mathrm{~min}$ at $4^{\circ} \mathrm{C}$ was subjected to immunoprecipitation with SR-12 antibody as described previously (Ramamoorthy et al., 1998a; Ramamoorthy and Blakely, 1999). To test specificity, additional experiments were performed in parallel using SR-12 preabsorbed serum as described previously (Ramamoorthy et al., 1998a; Ramamoorthy and Blakely, 1999). The immunoadsorbents captured by protein A Sepharose beads were washed with RIPA buffer before the addition of $60 \mu \mathrm{l}$ of Laemmli sample buffer and incubated for $30 \mathrm{~min}$ at $22^{\circ} \mathrm{C}$. The eluates were subjected to SDS-PAGE (10\%), and the radiolabeled proteins were detected on autoradiograms. Quantitation from digitized autoradiograms was evaluated on multiple exposures $(1,2,3$, and $7 \mathrm{~d})$ to ensure quantitation within the linear range of the film using NIH Image software.

Isolation of lipid raft by sucrose gradient centrifugation. Purified synaptosomes from midbrain were suspended in $5 \mathrm{mg}$ protein per milliliter of MBS buffer $(25 \mathrm{~mm}$ MES and $150 \mathrm{~mm} \mathrm{NaCl}, \mathrm{pH} 6.5$, containing $0.5 \%$ Triton X-100 and the following protease inhibitors: $1 \mu \mathrm{M}$ pepstatin A, $250 \mu \mathrm{M}$ PMSF, $1 \mathrm{mg} / \mathrm{ml}$ leupeptin, and $1 \mu \mathrm{g} / \mathrm{ml}$ aprotonin) (Becher et al., 2001). Synaptosomes were lysed using a Dounce homogenizer with 10 up and down strokes at $4^{\circ} \mathrm{C}$ followed by passing through a 27.1/2 gauge needle. Equal volumes of $80 \%$ (w/v) sucrose were added to the homogenate. All sucrose solutions contained the same buffer composition, detergent, and protease inhibitors. Lysed samples ( $4 \mathrm{ml}$ ) in $40 \%$ sucrose were overlaid successively with $4 \mathrm{ml}$ of $30 \%$ and $3 \mathrm{ml}$ of $5 \%$ sucrose in a Beckman SW41 ultracentrifuge tube. After centrifugation at $188,000 \times g$ for $18 \mathrm{hr}$ at $4^{\circ} \mathrm{C}, 1 \mathrm{ml}$ fractions were collected from the top. The pellet was resuspended in $1 \mathrm{ml}$ detergent buffer by brief sonication. Total proteins in each fraction were precipitated with $10 \%$ cold trichloroacetic acid, washed in acetone, air dried, and subjected to $4-15 \%$ linear gradient SDS-PAGE. The proteins were transferred to polyvinylidene difluoride membrane, and the presence of SERT and other proteins was determined by immunoblotting with specific antibodies as described previously (Jayanthi et al., 2004). For detection of the lipid raft marker ganglioside (GM1), $10 \mu$ l of each fraction was applied to a nitrocellulose membrane using dot-blot apparatus (Bio-Rad) and probed with $10 \mathrm{ng} / \mathrm{ml} \mathrm{CTXB}$.

Cell culture and transient transfections. HEK-293 cells were cultured as monolayers in DMEM media supplemented with $10 \%$ fetal bovine serum, $2 \mathrm{~mm}$ glutamine in 25 or $75 \mathrm{~cm}^{2}$ flasks in an atmosphere of $5 \% \mathrm{CO}_{2}$ and $95 \%$ humidity atmosphere at $37^{\circ} \mathrm{C}$. For transient transfection experiments, trypsin-released cells were seeded on 6-well (200,000 cells per well) or 24-well (50,000 cells per well) plates. Cells were transfected with different expression plasmids together with human SERT (hSERT) plasmids using Lipofectamine 2000 transfection reagent according to manufacturer's protocols. In all wells, the total amount of plasmid DNA was adjusted with corresponding empty vector. Where indicated, cells were treated with different modulators as described above after 12-24 hr of transfection.
5-HT uptake in transfected HEK-293 cells. 5-HT uptake was performed as described previously (Ramamoorthy and Blakely, 1999). Cells were preincubated with the modulators at $37^{\circ} \mathrm{C}$ for the indicated times followed by addition of $\left[{ }^{3} \mathrm{H}\right] 5-\mathrm{HT}$ to initiate 5 -HT uptake. Uptake was terminated after $10 \mathrm{~min}$ incubation at $37^{\circ} \mathrm{C}$ by rapid washings with $\mathrm{KRH}$ assay buffer containing $100 \mathrm{~nm}$ fluoxetine. Cells were lysed, and the accumulated radioactivity was measured by liquid scintillation. Specific 5HT uptake measurements were performed as described above.

Cell-surface biotinylation and immunoblotting. Cell-surface biotinylation on transfected cells was performed as described previously (Ramamoorthy and Blakely, 1999) after treatments with different modulators as indicated elsewhere. Biotinylated and nonbiotinylated SERT proteins were identified by immunoblotting with SERT-specific antibody.

RNA interference. The p38 MAPK interference was performed in HEK293 cells with SMARTpool p38 MAPK consisting of four pooled 21 RNA oligonucleotide-specific siRNAs. The unspecific scrambled sequence was used for control transfections. siRNA duplexes (200 nM) were transfected into cells using Lipofectamine 2000 according to manufacturer's instructions. At $12 \mathrm{hr}$ after transfection with siRNAs, cells were transfected with hSERT (100 ng per well). Twenty-four hours later, 5-HT uptake and surface biotinylations were performed as described previously. In parallel, suppression of $\mathrm{p} 38$ MAPK was verified by Western blotting with p38 MAPK-specific antibodies. The same blot was reprobed with anticalnexin to determine equal loading and nonspecific effect of siRNAs.

Assay of SERT endocytosis (reversible biotinylation). A reversible biotinylation strategy was used as described previously (Jayanthi et al., 2004). Transiently transfected HEK-293 cells were cooled rapidly to $4^{\circ} \mathrm{C}$ to inhibit endocytosis by washing with cold PBS and surface biotinylated with a disulfide-cleavable biotin (sulfo-NHS-SS-biotin; Pierce), and free biotinylating reagent was removed by quenching with glycine. SERT endocytosis was initiated by incubating the cells with prewarmed media containing the vehicle or PD169316 or $\beta$-PMA for indicated time periods at $37^{\circ} \mathrm{C}$. At the end of each time point, the reagents were removed, and fresh prechilled media were added to stop the endocytosis. The cells were then washed and incubated twice with $250 \mu \mathrm{M}$ sodium 2-mercaptoethanesulfonate (MesNa), a reducing agent, in PBS/Ca-Mg for 20 min to dissociate the biotin from cell surface-resident proteins via disulfide exchange. To define total biotinylated SERTs, one dish of biotinylated cells per condition was not subjected to reduction with $\mathrm{MesNa}$ and processed directly for extraction followed by isolation by avidin beads. To define MesNa-accessible SERTs, another dish of cells was treated with MesNa immediately (at 0 time) after biotinylation at $4^{\circ} \mathrm{C}$ to reveal the quantity of surface SERT biotinylation that MesNa can reverse efficiently.

At the end of the treatments, cells were solubilized in RIPA, and biotinylated SERTs were separated from nonbiotinylated proteins by using monomeric avidin beads. Biotinylated proteins were eluted from beads and resolved by SDS-PAGE. SERT proteins in the fractions were visualized using the SERT-specific antibody, SR-12. SERT bands were scanned, and the band densities were quantified by NIH Image 1.62 software.

Assay of SERT delivery to the plasma membrane. Cell surface biotinylation was performed at $37^{\circ} \mathrm{C}$ as described previously (Loder and Melikian, 2003; Fournier et al., 2004). Briefly, transfected HEK-293 cells were washed with $\mathrm{PBS} / \mathrm{Ca} / \mathrm{Mg}$ and incubated with NHS-SS-biotin $(1 \mathrm{mg} / \mathrm{ml})$ at $37^{\circ}$ or $4^{\circ} \mathrm{C}$ for $30 \mathrm{~min}$ with vehicle, PD169316, and $\beta$-PMA. After washing of the cells with cold $\mathrm{PBS} / \mathrm{Ca} / \mathrm{Mg}$ containing glycine, biotinylated SERTs were analyzed as described above.

Statistical analyses. Values are expressed as mean \pm SEM. Analysis by one-way ANOVA was used followed by post hoc testing (Tukey-Kramer and Bonferroni). Student's $t$ test was performed for paired observations. A value of $p<0.05$ was considered statistically significant.

\section{Results \\ p38 MAPK, but not ERKs or JNKs, is involved in the downregulation of native SERT}

Treatment of synaptosomes with the p38 MAPK inhibitor, PD169316, decreased 5-HT uptake in a dose- and timedependent manner. The concentration $(10 \mu \mathrm{M})$ and time (30 
min) of treatment were chosen after testing the dose $(0.625-20 \mu \mathrm{M})$ and time dependence $(2.5-60 \mathrm{~min})$ of the effect of PD169316 on 5-HT uptake. A significant inhibition of 5-HT uptake was observed at $10 \mu \mathrm{M}(\sim 35 \%)$ and $20 \mu \mathrm{M} \quad(\sim 55 \%)$ PD169316 (Fig. 1A) when treated for 30 min. A significant (23\%) inhibition was also observed at $10 \mu \mathrm{M}$ PD169316 when treated for a short time $(2.5 \mathrm{~min})$, and a maximum inhibition $(\sim 50 \%)$ was observed after a $10 \mathrm{~min}$ incubation time (Fig. $1 B)$. Another specific p38 MAPK inhibitor, SB203580 (10 $\mu \mathrm{M} ; 30 \mathrm{~min}$ incubation), also decreased SERT activity (Fig. $1 C)$. On the contrary, the MAP kinase kinase (MEK)-1 and MEK-2 inhibitors, PD98059, U0126 (1-50 $\mu \mathrm{M} ; 30 \mathrm{~min}$ incubation), or JNK inhibitor, SP600125 (1-50 $\mu \mathrm{M} ; 30-60 \mathrm{~min}$ incubation) did not affect SERT activity significantly (Fig. 1C). p38 MAPK is activated by phosphorylation by MKK3/6. We investigated the level of phosphorylated p38 MAPK and total p38 MAPK in midbrain synaptosomes. Immunoblot analysis revealed a high level of phosphorylated p38 MAPK in untreated synaptosomes (Fig. 1D). Treatment of synaptosomes with PD169316 (10 $\mu \mathrm{M} ; 30$ min) or SB203580 (10 $\mu \mathrm{M} ; 30 \mathrm{~min})$ did not affect the levels of phospho-p38 MAPK but inhibited p38 MAPK activity as evidenced in decreased levels of phosphoMAPKAPK (direct substrate for p38 MAPK) consistent with the fact that PD169316 and SB203580 inhibit only p38 MAPK catalytic activity (Fig. $1 D$ ). Treatment of synaptosomes with PD98059 (10 $\mu \mathrm{M}$; $30 \mathrm{~min}), \mathrm{U} 0126$ (10 $\mu \mathrm{M}$; $30 \mathrm{~min})$, or SP600125 (5 $\mu \mathrm{M} ; 30 \mathrm{~min})$ did not affect the levels of phospho-p38 MAPK. Total expression of p38 MAPK and MAPKAPK was unaltered by treatment of synaptosomes with any of these compounds (Fig. 1D).

The kinetic parameters of the SERT (Michaelis-Menten constant, $K_{\mathrm{m}}$, and maximal velocity, $\left.V_{\max }\right)$ were determined in vehicle and PD169316 (10 $\mu \mathrm{M} ; 30 \mathrm{~min})$ treated midbrain synaptosomes (Fig. 2). PD169316 treatment decreased the maximal velocity $\left(V_{\max }\right)$ by $\sim 40 \%$ (from $2734.4 \pm 50.4 \mathrm{fmol} / \mathrm{mg}$ protein per minute to $1716.5 \pm 59.8 \mathrm{fmol} / \mathrm{mg}$ protein per minute) with a reduction in the $K_{\mathrm{m}}\left(K_{\mathrm{m}}\right.$ values: control, $30.19 \pm 1.2 \mathrm{nM}$; PD169316, $19.87 \pm$ $2.1 \mathrm{nM})$.

p38 MAPK-mediated SERT downregulation is distinct from PKC-mediated SERT downregulation

Because PKC is a possible upstream activator of p38 MAPK and PKC downregulates SERT, we tested whether SERT inhibition by PD169316 is linked to PKC-mediated effects. Treatment of synaptosomes with the PKC activator, $\beta$-PMA alone, inhibited SERT activity, suggesting that PKC activation leads to SERT inhibition
B

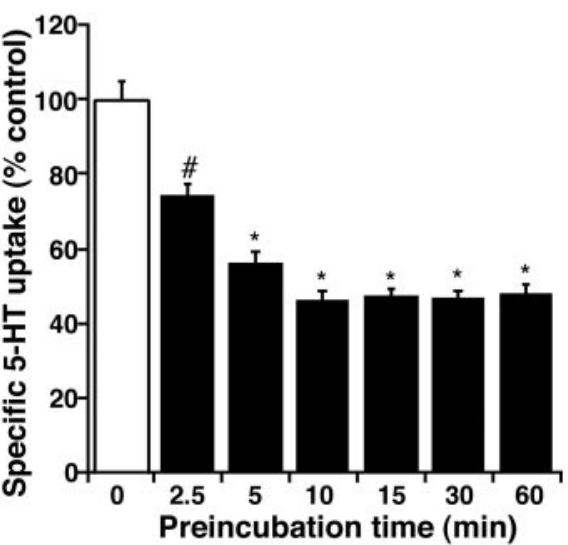

D
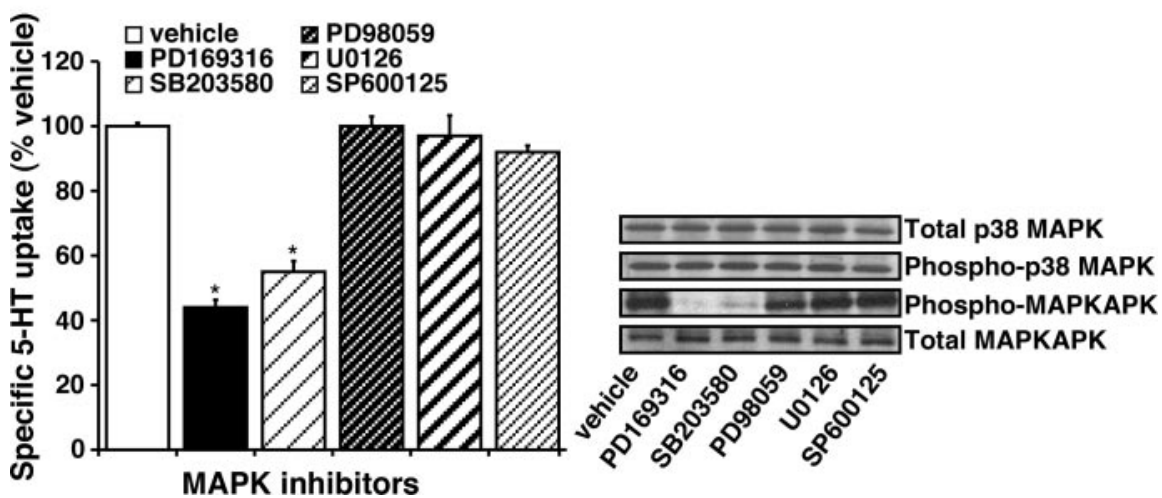

Figure 1. Regulation of 5-HT uptake by P38 MAPK inhibitor PD169316. A, Dose dependence of PD169316 on 5-HT uptake. Synaptosomes $(50 \mu \mathrm{g})$ were preincubated with various concentrations of PD169316 for $1 \mathrm{hr}$ at $37^{\circ} \mathrm{C}$ followed by 3 min 5 -HT uptake assays. Controls received the same volume of vehicle (DMSO). B, Time course effect of PD169316 on 5-HT uptake. Purified midbrain synaptosomes (50 $\mu \mathrm{g}$ ) were preincubated with $10 \mu \mathrm{M}$ PD169316 for the times indicated and then assayed for 5-HT (20 uptake in the presence of $0.1 \mu \mathrm{m}$ fluoxetine and subtracted from the total accumulation to yield specific uptake. The results were expressed as a percentage of uptake relative to the uptake observed in vehicle-treated synaptosomes, and data represent mean \pm SEM of three experiments performed in triplicate. ${ }^{*} p<0.05,{ }^{*} p<0.01$ compared with vehicle control by one-way ANOVA with Bonferroni post hoc analysis. C, Specificity of p38 MAPK inhibition on SERT function. Synaptosomes were treated for

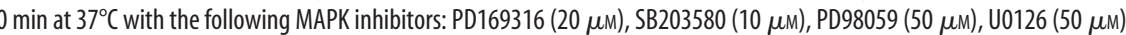
and SP600125 (50 $\mu \mathrm{m})$. 5-HT uptake was measured as described in A. D, Constitutive expression of p38 MAPK in untreated synaptosomes and the effect of MAPK inhibitors on 338 MAPK activity. Synaptosomes were treated with various MAPK inhibitors SDS-PAGE (as described in Materials and Methods). Immunoblotting was performed using specific antibodies to p38 MAPK, MAPKAPK, phospho-p38 MAPK, and phospho-MAPKAPK as indicated by arrows. Representative immunoblots from three independent experiments are shown.

(Table 1). Because inhibition of p38 MAPK also leads to downregulation of SERT, it is possible that constitutively active PKCs may be involved in maintaining basal SERT activity (constitutive SERT expression) via activated basal MAPKs (by activating p38 MAPK); however, there was an additive inhibitory effect when $\beta$-PMA was added together with PD169316, suggesting that SERT downregulation by PD169316 is not linked to PKC signaling. Furthermore, staurosporine, a broad-spectrum kinase inhibitor, as well as BIM I, a more selective PKC inhibitor, completely blocked $\beta$-PMA-induced inhibition but did not block the PD169316 effect (Table 1). When both $\beta$-PMA and PD169316 were used together, the inhibitory effect was near additive, and staurosporine partially blocked this additive inhibition, suggest- 


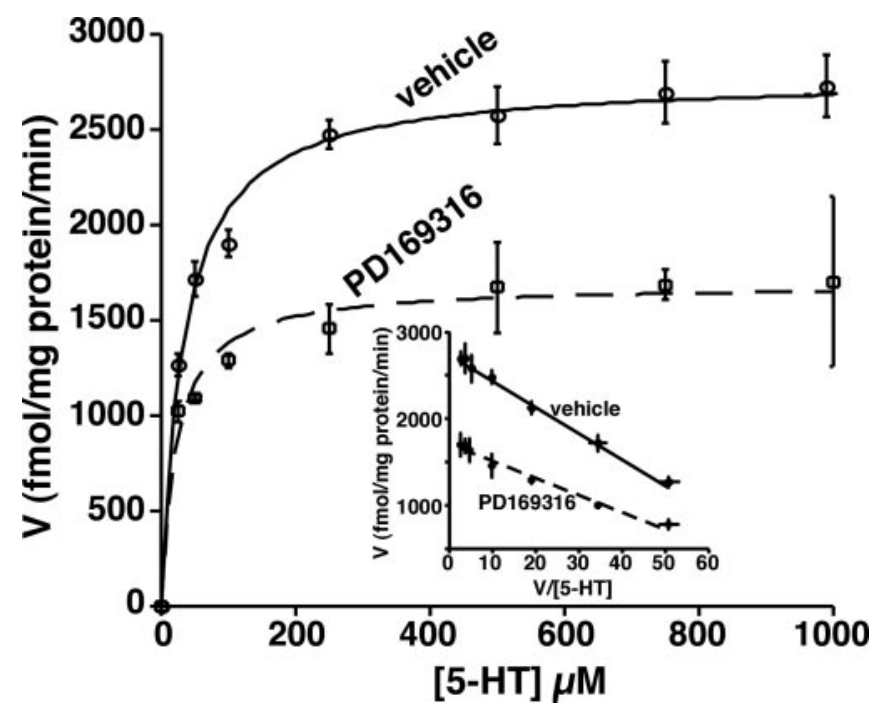

Figure 2. 5-HT uptake kinetics in vehicle and PD169316-treated synaptosomes. Synaptosomes $(50 \mu \mathrm{g})$ were preincubated with the vehicle or $10 \mu \mathrm{m}$ PD169316 for 30 min at $37^{\circ} \mathrm{C}$. After this treatment, uptake of 5 -HT was measured over a concentration range of $0.01-1 \mu \mathrm{m}$ using a 3 min uptake period. In parallel, nonspecific uptake at each concentration of 5-HT used (in the presence of $0.1 \mu \mathrm{m}$ fluoxetine) was subtracted from total uptake to calculate SERT-mediated 5-HT uptake. Values are the averages from four independent experiments, and the mean values \pm SEM are given. Nonlinear curve fits of data for uptake used the generalized MichaelisMenten equation (Kaleidagraph). When not shown, error is contained within the symbol. The inset shows an Eadie-Hofstee plot of transformation of the data.

Table 1. Specificity and coordinate effects of PD169616- and $\beta$-PMA-induced inhibition of SERT activity in rat midbrain synaptosomes

\begin{tabular}{lcc}
\hline Treatments & $\begin{array}{l}\text { SERT activity } \\
\text { (\% control) }\end{array}$ & $\begin{array}{c}\text { Percentage } \\
\text { of inhibition }\end{array}$ \\
\hline Vehicle & $100.00 \pm 0.05$ & 0.00 \\
PD169316 & $64.78 \pm 3.00$ & $35.22^{a}$ \\
$\beta$-PMA & $74.95 \pm 2.16$ & $25.05^{a}$ \\
PD169316 plus $\beta$-PMA & $47.16 \pm 1.98$ & $52.84^{a, b}$ \\
Staurosporine & $97.26 \pm 3.90$ & $2.74^{c}$ \\
Staurosporine plus PD169316 & $59.78 \pm 3.30$ & $40.22^{a}$ \\
Staurosporine plus $\beta$-PMA & $98.01 \pm 2.64$ & $1.99^{c}$ \\
Staurosporine plus PD169316 plus $\beta$-PMA & $63.95 \pm 3.16$ & $36.05^{a, d}$ \\
BIM I & $102.26 \pm 1.25$ & $0.00^{c}$ \\
BIM I plus PD169316 & $53.78 \pm 1.29$ & $46.22^{a}$ \\
BIM I plus $\beta$-PMA & $102.99 \pm 5.84$ & $0.00^{c}$ \\
BIM I plus PD169316 plus $\beta$-PMA & $69.05 \pm 4.23$ & $30.95^{a, d}$ \\
\hline
\end{tabular}

Purified rat midbrain synaptosomes were preincubated for $30 \mathrm{~min}$ at $37^{\circ} \mathrm{C}$ in the absence (vehicle) or presence of the following agents: PD169316, $10 \mu \mathrm{m} ; \beta$-PMA, $1 \mu \mathrm{m}$; bisindolylmaleimide I, $500 \mathrm{~nm}$; and staurosporine, $2.5 \mu \mathrm{M}$. Protein kinase C inhibitor staurosporine and BIM I were added $20 \mathrm{~min}$ before the addition of PD169316, $\beta$-PMA, or both. 5 -HT uptake was performed as described in Materials and Methods. Experiments were conducted in triplicate, and the mean values \pm SEM from three independent experiments are given. Significant differences were determined by one-way ANOVA with a Tukey-Kramer post hoc test.

${ }^{a}$ Significantly different from levels observed under vehicle conditions; $p<0.01$.

${ }^{b}$ Significantly different from the levels observed with the application of single modulator (PD169316 or $\beta$-PMA); $p<0.05$.

Not statistically different from the levels observed under vehicle conditions.

${ }^{d}$ Significantly different from the levels observed with coapplication of PD169316 and $\beta$-PMA; $p<0.05$

ing again that the effects of PD169316 are not linked to PKC signaling.

p38 MAPK-mediated but not PKC-mediated downregulation of SERT is calcium independent

PD169316 (10 $\mu \mathrm{M})$ inhibited 5-HT uptake even after calcium chelation, and the degree of inhibition remained the same after addition of calcium, suggesting that p38 MAPK does not require calcium to inhibit SERT activity (Fig. 3). After calcium chelation,

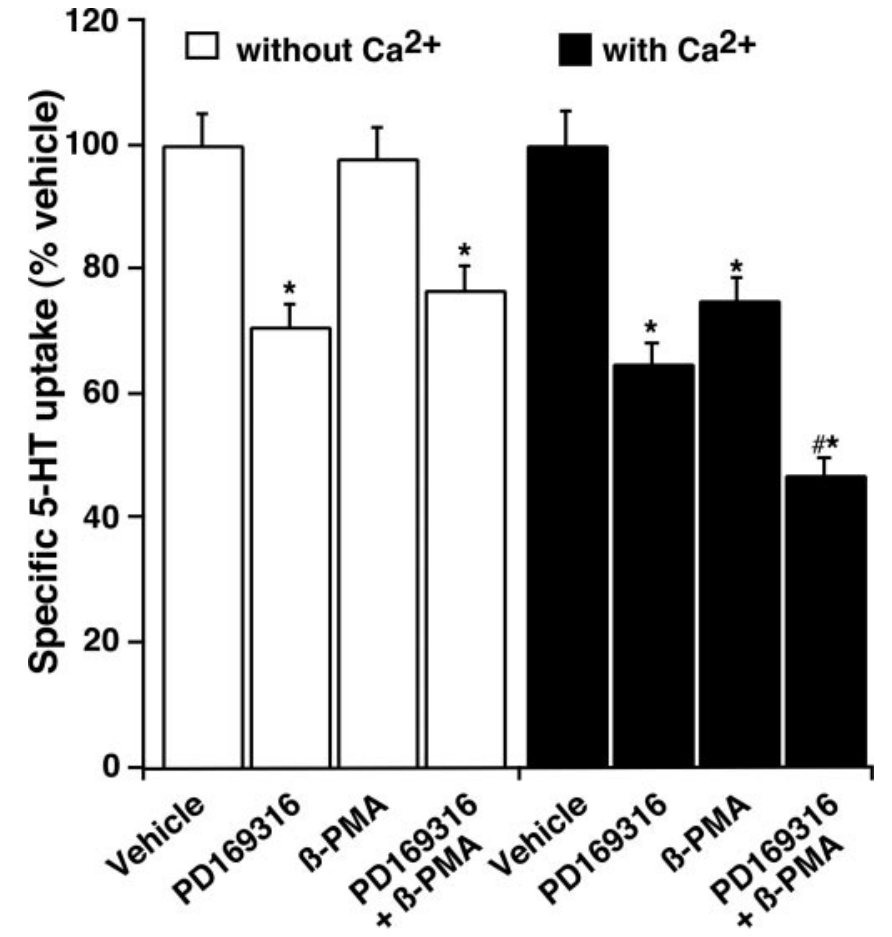

Figure 3. Effect of $\mathrm{Ca}^{2+}$ on PD169316- and $\beta$-PMA-induced inhibition of 5-HT uptake. Synaptosomes were treated with modified Krebs'- bicarbonate buffer to remove $\mathrm{Ca}^{2+}$ followed by incubation with PD169316 (10 $\mu \mathrm{M})$ or $\beta$-PMA (1.0 $\mu \mathrm{m})$ or PD169316 plus $\beta$-PMA for $30 \mathrm{~min}$ in the presence or absence of $\mathrm{Ca}^{2+}$ as described (see Materials and Methods). 5-HT uptake was measured using $20 \mathrm{~nm}$ labeled 5 - $\mathrm{HT}$ for $3 \mathrm{~min}$. Parallel assays were conducted in the presence of vehicle and $0.1 \mu \mathrm{m}$ fluoxetine to define the effect of vehicle and SERT-specific uptake. The mean uptake values \pm SEM from three independent experiments performed in triplicate are given. ${ }^{*} p<0.05$ denotes significant changes compared with vehicle controls; ${ }^{\#} p<0.01$ denotes values significantly different from PD169316 or $\beta$-PMA alone in normal $\mathrm{Ca}^{2+}$-containing buffer (one-way ANOVA with Bonferroni post hoc analysis).

however, $\beta$-PMA $(1.0 \mu \mathrm{M})$ failed to inhibit 5-HT uptake, but inhibition was restored when calcium was added into the assay buffer, suggesting that PKC-mediated SERT inhibition is calcium dependent (Fig. 3). In addition, the inhibition of SERT activity was additive when $\beta$-PMA and PD169316 were added together in the presence of calcium (Fig. 3). In the absence of calcium, the inhibition was similar to that obtained with PD169316 alone (Fig. 3 ). These data further suggest that although PKC-mediated effects on SERT are strictly calcium dependent, the effects of p38 MAPK on SERT are not.

\section{p38 MAPK-mediated sequestration of native SERT}

Figure $4 A$ shows a significant decrease in the amount of immunoreactive SERT proteins that were surface biotinylated after treatments with PD169316 $(10 \mu \mathrm{M})$ or $\beta$-PMA $(1.0 \mu \mathrm{M})$ or PD169316 $(10 \mu \mathrm{M})$ plus $\beta$-PMA $(1.0 \mu \mathrm{M})$. Either PD169316 or $\beta$-PMA decreased SERT immunoreactivity to nearly $70 \pm 5 \%$ of control value in the biotinylated fraction and significantly increased the amount of nonbiotinylated intracellular transporter (Fig. 4A, B). There was an additive decrease in SERT immunoreactivity to $\sim 45 \pm 5 \%$ of vehicle control when both PD169316 and $\beta$-PMA were added together; a concomitant increase in intracellular SERT was observed (Fig. 4A,B). There was no change in the total SERT protein expression as measured by immunoblotting (Fig. 4A). Quantified band densities are presented in Figure $4 B$. Treatment with PD169316 or $\beta$-PMA had no effect on the total amount of calnexin, and $<0.3 \%$ of total calnexin was present in 
A

SERT

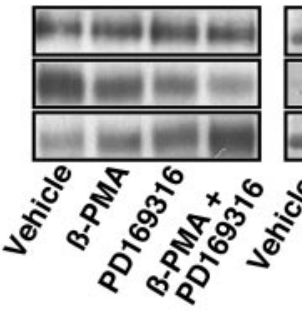

B

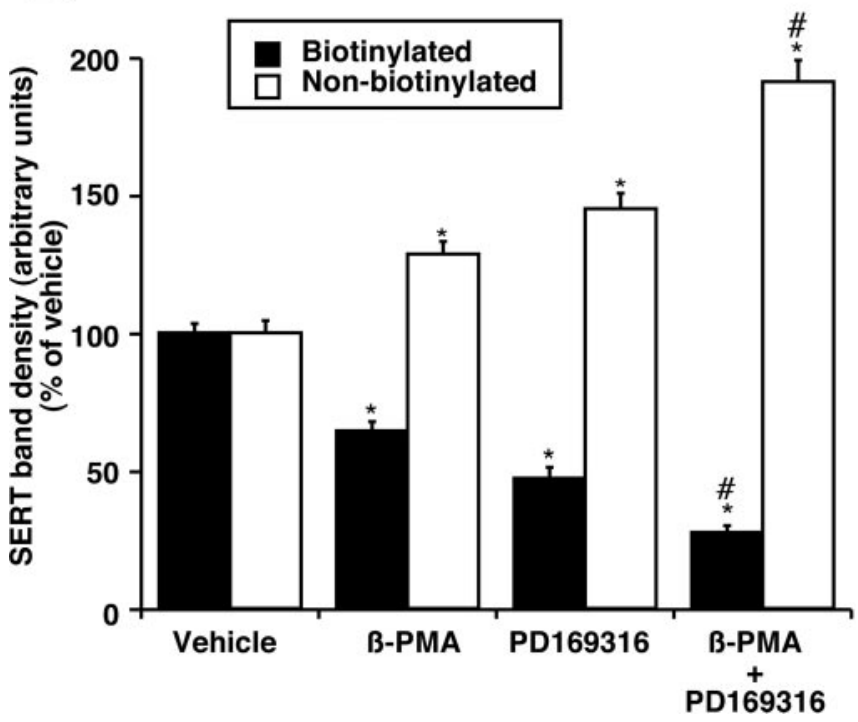

Figure 4. Effect of PD169316 and $\beta$-PMA on cell-surface SERT density. A,SERT immunoblot. Synaptosomes were treated with $10 \mu \mathrm{M}$ PD169316 or $1 \mu \mathrm{M} \beta$-PMA and/or vehicle for $30 \mathrm{~min}$. After the treatments, biotinylation with sulfo-NHS-SS-biotin was performed (as described in Materials and Methods). Aliquots (50 $\mu \mathrm{l}$ ) of total, nonbiotinylated, and entire biotinylated fractions were subjected to SDS-PAGE followed by immunoblotting with affinity-purified SR-12 SERT antibody. A representative SERT immunoblot of four separate experiments is shown. $B$, Quantitative analysis of SERT band densities. Biotinylation of SERT proteins was quantified using NIH Image, and the densities of SERT band from three separate experiments are presented as mean \pm SEM. ${ }^{*} p<0.05$ indicates significant changes in cell surface and intracellular SERT after $\beta$-PMA or PD169316 treatment compared with vehicle treatment. ${ }^{*} p<0.01$ denotes significant differences compared with PD169316 or $\beta$-PMA alone (one-way ANOVA with Bonferroni post hoc analysis).

avidin-bound fractions (Fig. 4A), suggesting that most of the synaptosomes in the preparation were intact and intracellular proteins were not significantly biotinylated.

Both PD169316 and $\beta$-PMA affect SERT association with PP2Ac and syntaxin 1A

Previously, using a transfected HEK-293 cell line that stably expresses hSERT and rat brain, we demonstrated that PP2Ac is recoverable from SERT immuno-isolates and that the PKC activation decreased PP2Ac in SERT immune complexes (Bauman et al., 2000). SERT also interacts with syntaxin $1 \mathrm{~A}$, and PKC activation decreases its association with SERT (Haase et al., 2001; Quick, 2002). Because the PKC- and p38 MAPK-mediated SERT downregulation is additive, we investigated the presence of PP2Ac and syntaxin 1A in a SERT immune complex isolated from synaptosomes treated with vehicle, $\beta$-PMA, and PD169316. Both $\beta$-PMA and PD169316 treatments reduced the association of SERT with PP2Ac or syntaxin 1A (Fig. $5 A, B$ ).
A IP: SERT-Ab

IP: Pre-Immune IgG
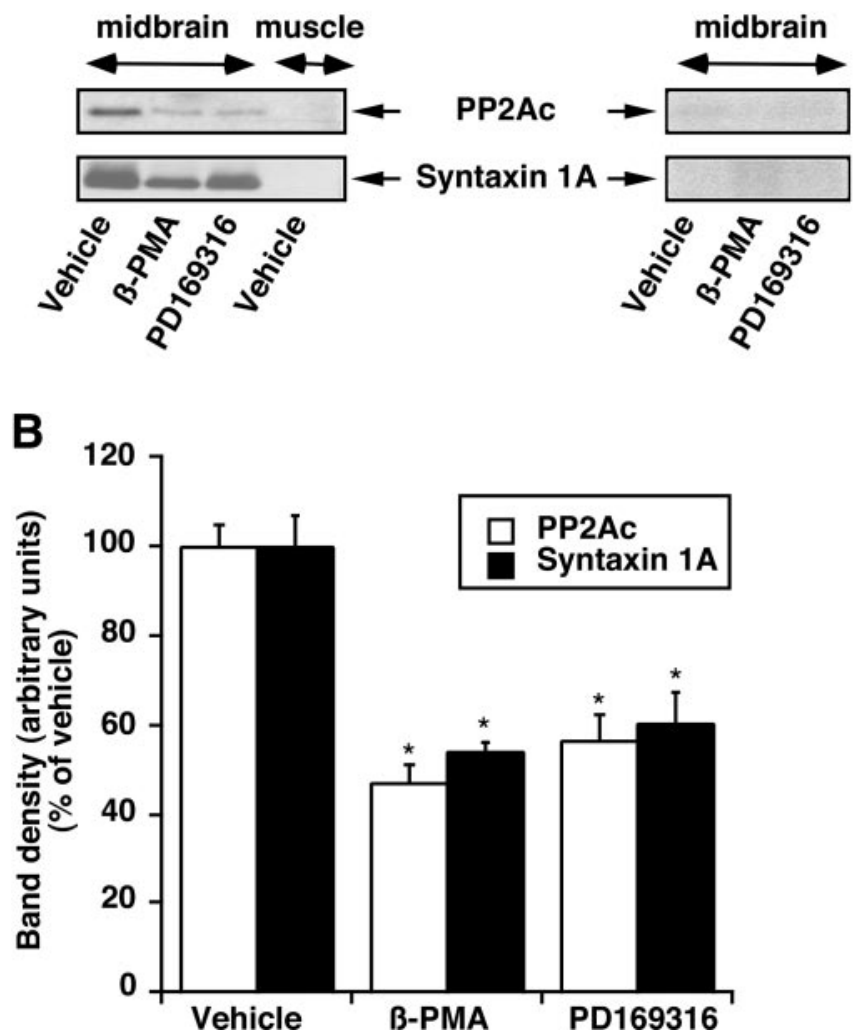

Figure 5. Effect of PD169316 and $\beta$-PMA on SERT-PP2Ac or SERT-syntaxin $1 A$ interaction. Synaptosomes were treated with $10 \mu \mathrm{M}$ PD169316 or $1 \mu \mathrm{M} \beta$-PMA and/or vehicle for $30 \mathrm{~min}$. The synaptosomes were solubilized and immunoprecipitated with the SERT-specific antibody SR-12. Immunoprecipitates were subjected to SDS-PAGE and immunoblot analysis for PP2Ac or syntaxin $1 \mathrm{~A}$ (as described in Materials and Methods). Parallel experiments using muscle extract and preimmune lgG were performed to validate the specificity of SERT-specific antibody SR-12 and SERT interactions. Note that no PP2Ac or syntaxin $1 A$ is seen in muscle extract using SR-12 antibody or in midbrain extract using preimmune $\operatorname{lgG}$. $A$, Representative immunoblots are shown for SERT-PP2Ac and SERT-syntaxin $1 A$ associations from synaptosomes treated with 10 $\mu \mathrm{m}$ PD169316 or $1 \mu \mathrm{m} \beta$-PMA and or vehicle. $B$, The bar plot displays averaged protein band densities from three separate experiments that are presented \pm SEM. ${ }^{*} p<0.01$; significant differences compared with vehicle-treated controls (one-way ANOVA with Tukey-Kramer post hoc analysis).

\section{Differential influence of PD169316 and $\beta$-PMA on SERT basal phosphorylation}

Because activation of PKC, a serine-threonine kinase, stimulates SERT phosphorylation and MAP kinases belong to a family of serine-threonine kinases, the phosphorylation state of SERT was examined after PD169316 (10 $\mu \mathrm{M}), \beta$-PMA (1 $\mu \mathrm{M})$, or vehicle treatment. Phosphorylation of a protein band corresponding to SERT was increased several-fold after $\beta$-PMA treatment (Fig. $6 A, B$ ). SERT phosphorylation is observed in the absence of any modulator and is considered basal SERT phosphorylation (Fig. $6 A, B)$. Interestingly, after PD169316 treatment, there was a significant decrease in the basal phosphorylation of SERT. $\beta$-PMAstimulated SERT phosphorylation remained unchanged when $\beta$-PMA and PD169316 were coapplied at maximally effective concentrations (Fig. 6A, $B$ ); however, preincubation with staurosporine before the addition of $\beta$-PMA completely abolished $\beta$-PMA-triggered SERT phosphorylation but did not affect SERT basal phosphorylation or the inhibitory effect of PD169316 on SERT basal phosphorylation (Fig. $6 A, B$ ). The effect of $\beta$-PMA and PD169316 on SERT basal phosphorylation in synaptosomes 


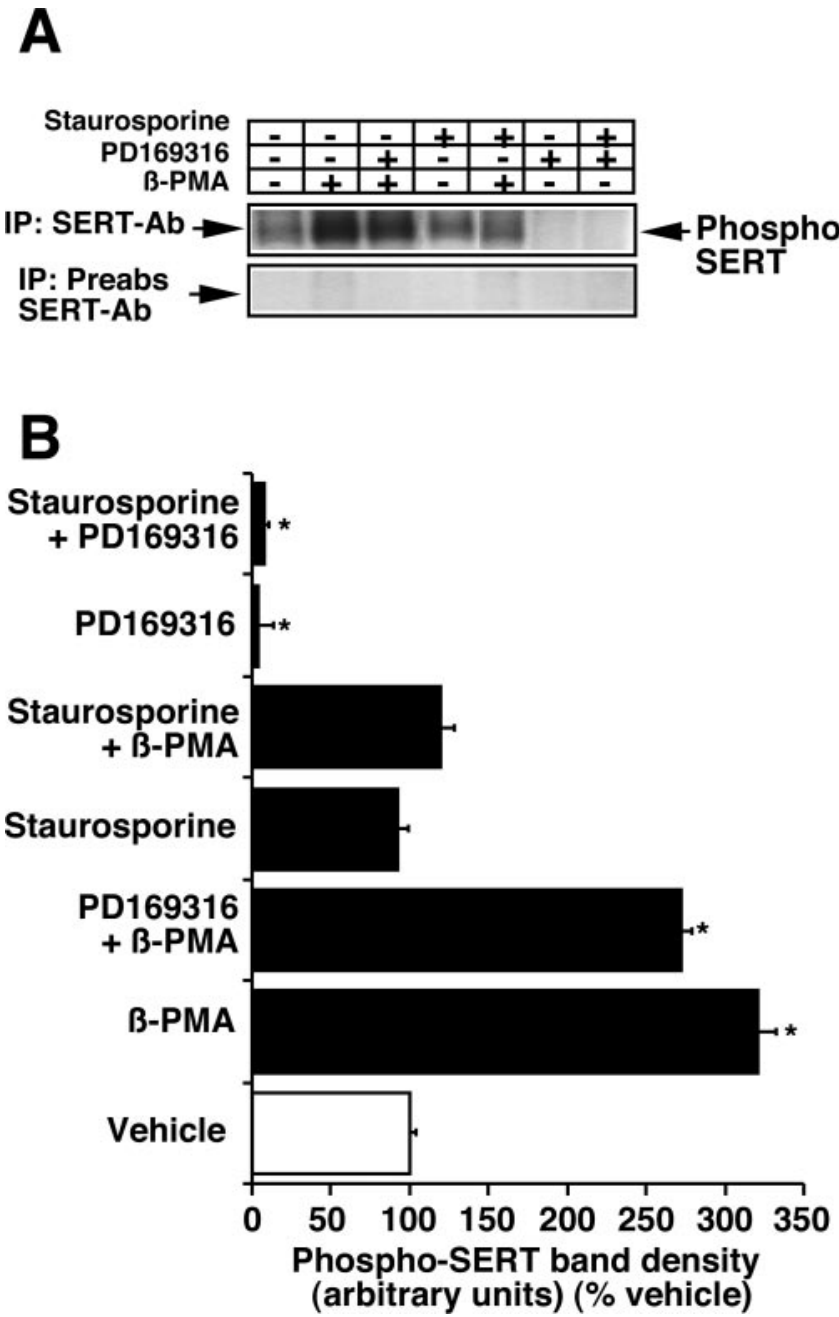

Figure 6. Effect of PD169316 and $\beta$-PMA on SERT basal phosphorylation. Synaptosomes were incubated in phosphate-free oxygenated buffer containing $5 \mathrm{mCi} / \mathrm{ml}^{32} \mathrm{P}$ carrier-free orthophosphate for $30 \mathrm{~min}$ at $37^{\circ} \mathrm{C}$. PD169316 $(10 \mu \mathrm{M})$ or $\beta$-PMA $(1 \mu \mathrm{m})$ or vehicle was added and further incubated for $30 \mathrm{~min}$. Detergent extraction, immunoprecipitation, SDS-PAGE, and autoradiography were performed (as described in Materials and Methods). A, An autoradiogram of immunoprecipitates as a representative of three experiments is shown. The position of ${ }^{32} \mathrm{P}$-labeled SERT is marked on the right. Parallel experiments were performed using preabsorbed SERT antibody SR-12 to validate the specificity of the SERT-specific antibody SR-12. Note that no ${ }^{32}$ P-labeled SERT band is seen using preabsorbed SR-12 antibody. B, Quantitation of ${ }^{32} \mathrm{P}$-labeled SERT. Autoradiograms of three experiments were analyzed as described in Materials and Methods. ${ }^{*} p<0.001$; values significantly different from vehicle control (one-way ANOVA with Bonferroni post hoc analysis).

was identical after metabolic labeling with ${ }^{32} \mathrm{P}$ for 30,45 , or 60 min (data not shown).

p38 MAPK inhibition abolishes D-amphetamine-induced increase in SERT basal phosphorylation

Previously, we demonstrated that the SERT substrates 5-HT, D-amphetamine, and fenfluramine blunted PKC-mediated SERT phosphorylation (Ramamoorthy and Blakely, 1999). To avoid activation of the 5-HT receptor-signaling cascade in synaptosomes by 5 -HT application, D-amphetamine was used as a SERT substrate to examine the interaction of SERT substrate on p38 MAPK-mediated SERT basal phosphorylation. In the presence of $\mathrm{Na}^{+}$and $\mathrm{Cl}^{-}$, D-amphetamine significantly increased SERT basal phosphorylation (Fig. 7). Individual substitution for $\mathrm{Na}^{+}$ or $\mathrm{Cl}^{-}$almost reversed the ability of $\mathrm{D}$-amphetamine to increase

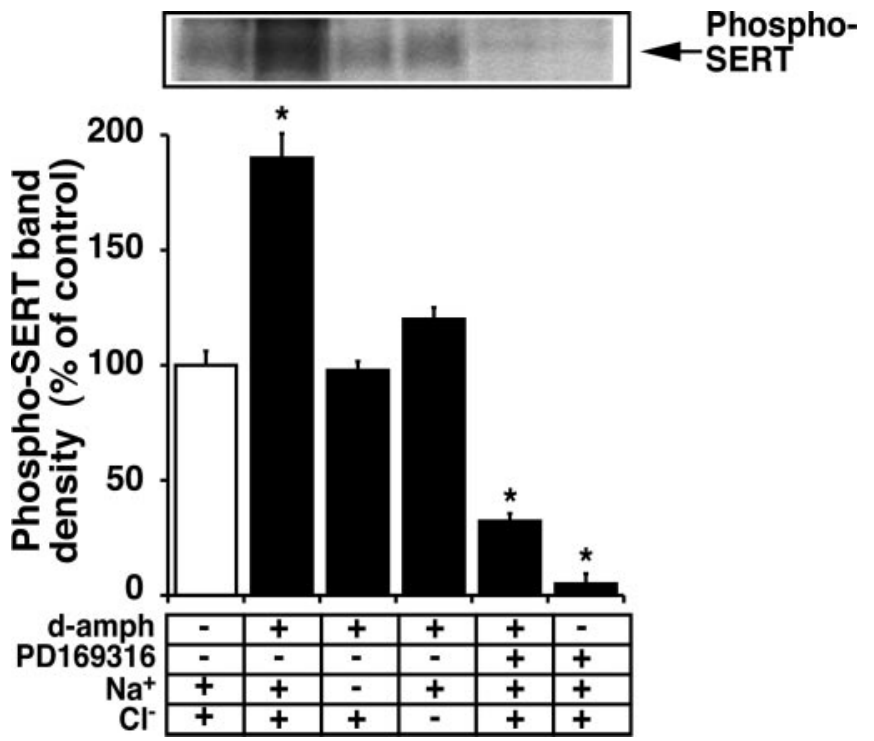

Figure 7. Interaction of D-amphetamine and PD619316 on SERT basal phosphorylation. D-Amphetamine $(1.0 \mu \mathrm{m})$ was added to metabolically labeled synaptosomes $15 \mathrm{~min}$ before and during PD169316 (10 $\mu \mathrm{m})$ application for $30 \mathrm{~min}$, and SERT phosphorylation was evaluated as described previously (Ramamoorthy and Blakely, 1999) and in the legend to Figure 6. A representative autoradiogram of SERT immunoprecipitates and averaged phospho-SERT band densities from three independent experiments are shown. ${ }^{*} p<0.001$; values significantly different from vehicle control (one-way ANOVA with Bonferroni post hoc analysis).

SERT basal phosphorylation. Substitution of these ions had no effect on SERT basal phosphorylation, suggesting that D-amphetamine-mediated increase in SERT basal phosphorylation may be linked to D-amphetamine interactions with SERT. Interestingly, p38 MAPK inhibition by PD169316 not only inhibited SERT basal phosphorylation but also blunted the ability of D-amphetamine to influence SERT basal phosphorylation, suggesting that p38 MAPK governs the influence of SERT substrates on SERT basal phosphorylation (Fig. 7).

p38 MAPK inhibition does not redistribute SERT from lipid rafts, whereas $\mathrm{PKC}$ activation does

We demonstrated recently that the norepinephrine transporter (NET) is localized in lipid rafts, and downregulation of NET by PKC involves redistribution of the NET from lipid rafts (Jayanthi et al., 2004). To examine the role of lipid rafts in PKC- and p38 MAPK-mediated SERT regulation, we performed discontinuous sucrose gradient centrifugation to isolate lipid and nonlipid raft fractions followed by detection of SERT and other marker proteins. Immunoblot analysis of isolated fractions revealed the presence of SERT in lipid raft fractions (Fig. 8A, fractions 4-6). Approximately $20-25 \%$ of SERT immunoreactivity was found in lipid rafts (fractions 4-6) when compared with total SERT expression. Lipid raft markers such as caveolin and GM1 were coisolated with SERT (Fig. 8). The nonlipid raft marker $\mathrm{Na} / \mathrm{K}$ ATPase was present only in the later fractions (fractions 8-12) and was absent in lipid raft fractions (fractions 4-6). Treatment of synaptosomes with $\beta$-PMA ( $1 \mu \mathrm{M} ; 30 \mathrm{~min})$ decreased the band density of SERT in the lipid raft fractions, with a concomitant increase of SERT protein in the nonlipid raft fractions (Fig. 8C). In contrast, treatment of synaptosomes with PD169316 (20 $\mu \mathrm{M}$; $30 \mathrm{~min}$ ) showed no change in SERT distribution in lipid and nonlipid raft fractions (Fig. $8 \mathrm{~B}$ ). These results showed for the first time that SERT is localized in lipid raft microdomains and the PKC-mediated SERT downregulation involves redistribution of 
the SERT population from lipid rafts to nonlipid rafts. Furthermore, these results support the involvement of distinct trafficking pathways linked to PKC- and p38 MAPK-mediated SERT regulation.

\section{Cotransfection of SERT with a} constitutively active form of MKK3b stimulates SERT activity in HEK-293 cells

The above studies strongly suggest that SERT is differentially regulated by PKC and p38 MAPK in native synaptosomal preparations. We next sought to determine the potential cellular mechanisms involved in SERT downregulation by $\beta$-PMA and PD169316 using HEK-293 cells transiently expressing SERT. To elucidate the signaling pathway that links p38 MAPK to SERT regulation, constitutively active upstream kinase MKK3b(E) was expressed along with hSERT in HEK-293 cells. HEK-293 cells were transfected with hSERT plus the active form of MKK3b(E) or the vector, pcDNA3. Phospho-p38 MAPK, phospho-MAPKAPK, and SERT activities were examined $24 \mathrm{hr}$ later. MKK3b is the immediate upstream kinase that activates p38 MAPK by direct phosphorylation. As expected, expression of the MKK3-active form of kinase resulted in a one- to twofold increase in phosphop38 MAPK and -MAPKAPK (Fig. 9A). There was no change in the total p38 MAPK and MAPKAPK levels. 5-HT transport in cells transfected with hSERT plus the active form of $\mathrm{MKK} 3 \mathrm{~b}(\mathrm{E})$ was higher than that observed in cells transfected with hSERT plus pcDNA3 (Fig. 9B). There was no change in the level of total SERT expression in cells transfected with hSERT plus vector or hSERT plus MEK3b(E) (Fig. 9C). Biotinylation experiments showed a significant increase in surface biotinylation of SERT consistent with the increased SERT function after p38 MAPK activation (Fig. 9C). The stimulation of SERT activity, surface SERT density, and phospho-MAPKAPK were blocked by PD169316 (Fig. 9A-C). The increase in SERT activity was evident as early as 12 hr after transfection (data not shown).

The time course expression of the active form of MKK3 showed that activation of p38 MAPK is a prerequisite for the stimulation of SERT activity.

Inhibition of p38 MAPK expression by siRNA reduces 5-HT transport and SERT surface expression in HEK-293 cells To confirm the involvement of p38 MAPK in the regulation of SERT activity, the effect of loss of function of p38 MAPK was examined using siRNAs specific to p38 MAPK. Transfection of HEK-293 cells with hSERT and siRNA targeted to p38 MAPK resulted in a decrease in p38 MAPK expression and active $\begin{array}{ll}\text { B) PD169316 } & \text { C) B-PMA }\end{array}$

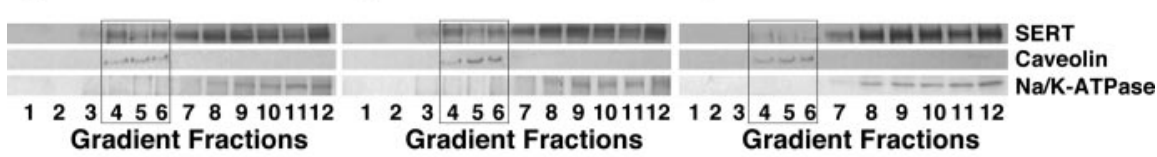
$\begin{array}{llllllllllllllll}\text { Gradient Fractions } & & \text { Gradient Fractions } & & \text { Gradient Fractions }\end{array}$

Figure 8. SERT localization in lipid rafts and effect of $\beta$-PMA and PD169316 on raft-associated SERT. Purified synaptosomes were pretreated with vehicle $(A)$, PD169316 $(20 \mu \mathrm{M})(B)$, and $\beta$-PMA (1 $\mu \mathrm{M})(C)$ for $30 \mathrm{~min}$ at $37^{\circ} \mathrm{C}$. Synaptosomes were extracted with $0.5 \%$ Triton X-100, and sucrose density gradients were performed as described in Materials and Methods. The proteins from fractions 1-12 (from top to bottom) were separated by SDS-PAGE and probed with antibodies against the indicated proteins. SERT proteins are found both in lipid raft fractions (boxed fractions $4-6$, confirmed by the presence of lipid raft markers caveolin and GM1) and in nonlipid raft fractions (fractions $8-12$, confirmed by the presence of $\mathrm{Na}{ }^{+} / \mathrm{K}^{+}$-ATPase). The localization of GM1 was detected by dot blotting with horseradish peroxidase-conjugated CTXB (as described in Materials and Methods). Representative immunoblots of three independent experiments are shown.
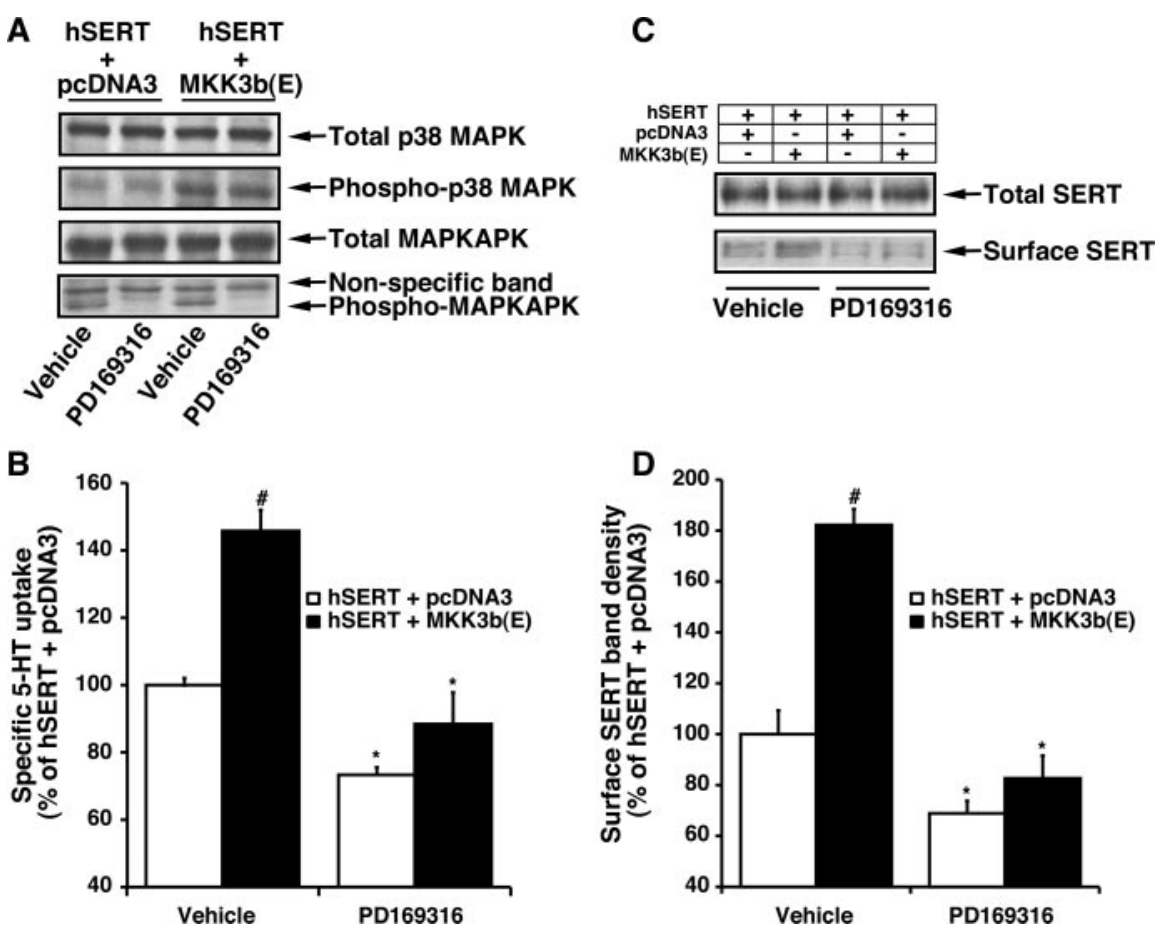

Figure 9. Induction of SERT activity in HEK-293 cells transfected with the active form of MKK3b(E). Cells were transfected with hSERT plus either pcDNA3 (empty vector) or the active form of MKK3b(E) (as described in Materials and Methods). After $24 \mathrm{hr}$, cells were washed once with KRH buffer and treated with PD169316 or the vehicle for 30 min at $37^{\circ} \mathrm{C}$. $\mathrm{A}$, Western blot analysis of phosphorylated form of p38 MAPK and MAPKAPK and total p38 MAPK and MAPKAPK. 5-HT uptake assays ( $B$ ), SERT expression using biotinylation procedures ( $C$, and quantitative SERT surface band density $(D)$ were performed (as described in Materials and Methods and in the legends to Figs. 1 and 4). The data shown in $B$ and $D$ are averages from three separate experiments, and data represent mean \pm SEM performed in triplicate. Values significantly different from SERT plus pcDNA3-transfected cells $\left({ }^{\#} p<0.01\right.$; Student's $t$ test); significant differences compared with vehicle-treated controls ( ${ }^{*} p<0.05$; Student'st test). Representative blots from three independent experiments are shown in $A$ and $C$.

phospho-p38 MAPK levels $24 \mathrm{hr}$ after transfection, in comparison with cells transfected with nonspecific scrambled siRNA and hSERT (Fig. 10A). Calnexin protein expression was not affected by transfection with siRNAs (Fig. 10A). The siRNA targeting p38 MAPK, but not scrambled RNA, significantly reduced 5-HT uptake (Fig. $10 \mathrm{~B}$ ). Transfection of scrambled siRNA or siRNA targeted to p38 MAPK had no effect on total expression of SERT (Fig. 10C); however, transfection of p38 MAPK siRNAs significantly reduced surface expression of SERT and increased intracellular SERT (Fig. 10C,D). These results indicate that p38 MAPK expression is necessary for efficient SERT expression. 


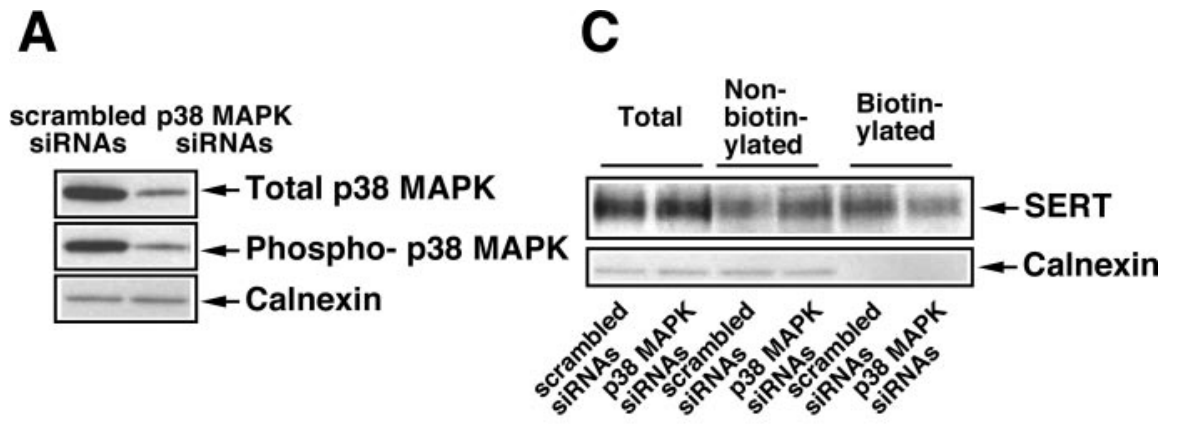

B
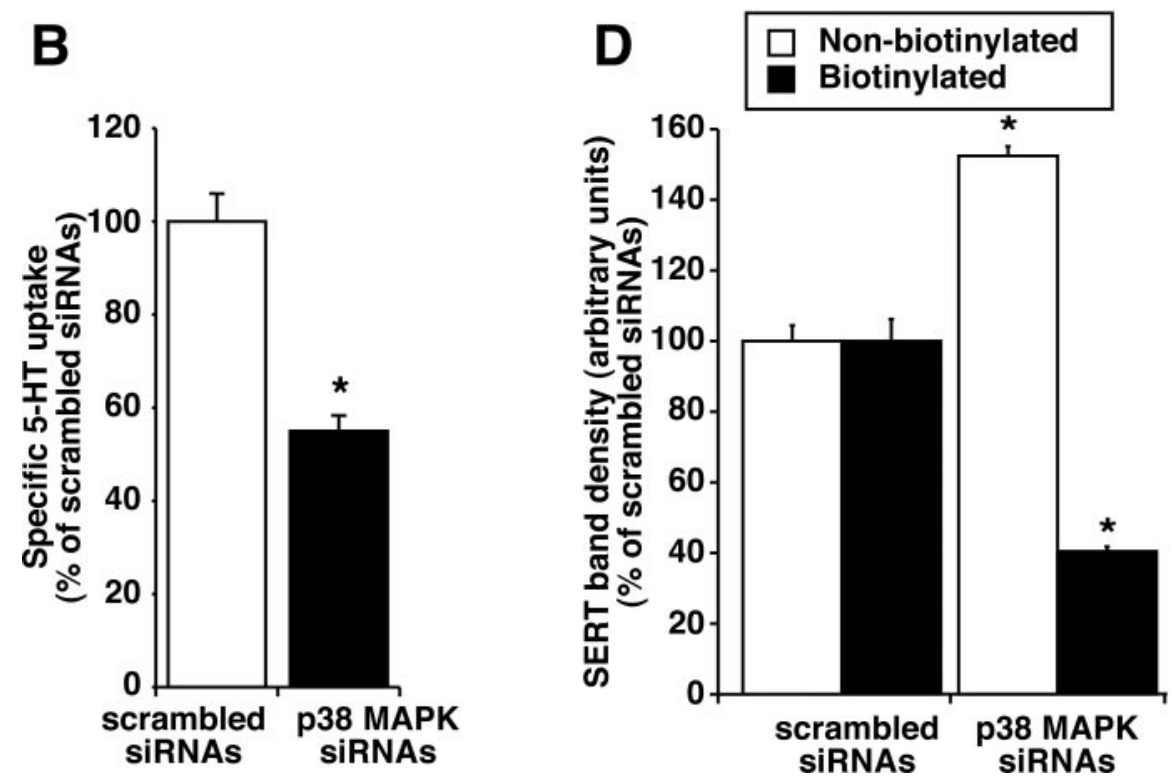

Figure 10. Effect of reducing p38 MAPK expression by siRNAs on 5-HT transport. HEK-293 cells were transiently transfected with $200 \mathrm{~nm}$ siRNAs targeted to p38 MAPK or scrambled siRNAs before the transfection with hSERT (as described in Materials and Methods). After $24 \mathrm{hr}$, cells were used for 5-HT transport, p38 MAPK expression, and SERT biotinylation as in Figure 9. A, A representative Western blot from three separate experiments shows the expression levels of total and phospho-p38 MAPK and calnexin. $B, 5$-HT uptake values are averages from three separate experiments, and data represent mean \pm SEM. C, D, SERT expression measurements using biotinylation procedures and quantitation of SERT surface band densities were performed (as described in Materials and Methods and in the legends to Figs. 1 and 4). Representative blots from three independent experiments are shown in C. The data shown in $D$ are averages of band densities from three separate experiments, and data represent mean \pm SEM. Values significantly different from SERT plus scrambled siRNAs transfected cells ( ${ }^{*} p<0.05$; Student's $t$ test).

\section{PKC activation but not p38 MAPK inhibition increases SERT} internalization in HEK-293 cells

Having observed a decrease in surface SERT density after $\beta$-PMA or PD169316 treatment, we next examined whether $\beta$-PMA or PD169316 treatment increases internalization of SERT from the cell surface. SERT internalization was examined using reversible biotinylation strategies and quantifying the surface biotinylated SERT that moves to an intracellular compartment. Biotin from biotinylated SERT remaining on the surface was removed by MesNa treatment at the end of vehicle, $\beta$-PMA, and PD169316 treatments. The amount of biotinylated SERT resistant to MesNa reversal was quantified as internalized SERT (Fig. $11 A, B)$. A significant increase in the amount of biotinylated SERT (internalized) was observed after $\beta$-PMA $(1 \mu \mathrm{M})$ treatment for $30 \mathrm{~min}$ at $37^{\circ} \mathrm{C}$ when compared with vehicle treatment. In contrast, PD169316 treatment showed no change in the MesNa-resistant biotinylated SERT fraction (Fig. 11A,B). These results provide evidence for differential cellular mechanisms involved in PKC and p38 MAPK-mediated SERT regulation and show that PKC activation but not p38 MAPK inhibition increases SERT internalization.
In HEK-293 cells, p38 MAPK inhibition but not PKC activation decreases delivery of SERT to the cell surface Although PD169316 had no effect on SERT internalization, the observed decrease in cell-surface SERT by PD169316 treatment (Fig. 11) may involve changes in SERT delivery to the cell surface. To evaluate the delivery of SERT to the cell surface, biotinylation was performed at $37^{\circ} \mathrm{C}$ (trafficking permissive conditions) and $4^{\circ} \mathrm{C}$ (trafficking nonpermissive conditions) in the presence of vehicle, $\beta$-PMA, or PD169316 for $30 \mathrm{~min}$ (Fig. 12). The amount of biotinylated SERT and transferrin receptor was higher at $37^{\circ} \mathrm{C}$ when compared with biotinylation performed at $4^{\circ} \mathrm{C}$ (Fig. 12A). The change in SERT biotinylation at $37^{\circ} \mathrm{C}$ was not caused by biotinylation of intracellular SERT because there was no change in the calnexin level in biotinylated fraction (Fig. 12A). Biotinylation at $37^{\circ} \mathrm{C}$ in the presence of $\beta$-PMA had no effect on the amount of SERT biotinylated; however, biotinylation in the presence of PD169316 significantly reduced the amount of SERT biotinylated when compared with vehicle (Fig. 12A,B). Under similar conditions, there was no evidence for changes in the amount of biotinylated transferrin receptor. These results suggest that PD169316, but not $\beta$-PMA, reduces SERT insertion (accessible to surface biotinylation) to the plasma membrane.

\section{Discussion}

This study demonstrates that in rat midbrain synaptosomes inhibition of p38 MAPK decreases 5-HT transport, and this effect results from a decreased transport capacity that is distinct from PKCmediated SERT downregulation. The decreased transport capacity results from a decrease in plasma membrane SERTs. The reduction in plasma membrane SERTs occurs because of reduced transporter delivery to the plasma membrane, as observed in HEK-293 cells. Cotransfection of the constitutively active form of MKK3b with SERT in HEK-293 cells increased 5-HT transport and surface SERT expression. A reduction of p38 MAPK expression by siRNAs in HEK-293 cells decreased 5-HT transport and surface SERT expression, suggesting a direct correlation between SERT function and p38 MAPK activity.

Recently, a selective MEK inhibitor, PD98059, has been shown to downregulate dopamine transporter (DAT), suggesting a role for MEK1/2 in DAT regulation (Lin et al., 2003; Moron et al., 2003); however, PD98059 had no effect on 5-HT transport. Similarly, SP600125, a specific inhibitor of JNK, also had no affect on 5-HT uptake. In contrast, PD169316, a selective p38 MAPK inhibitor, decreased synaptosomal 5-HT uptake and SERT surface expression, suggesting a role for $\mathrm{p} 38 \mathrm{MAPK}$ in the regulation of SERT function and expression. SB203580, a clinically used selective p38 MAPK inhibitor, also downregulated SERT. Furthermore, cotransfection of active MKK3b, the upstream kinase 
A

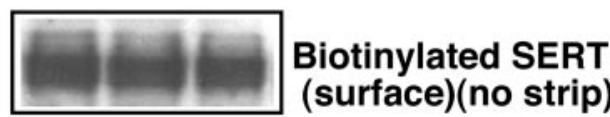

Biotinylated SERT $\left(4^{\circ} \mathrm{C}\right)$ (background)(after strip)

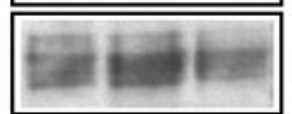

Biotinylated (internalized) SERT $\left(37^{\circ} \mathrm{C}\right)$ (after strip)

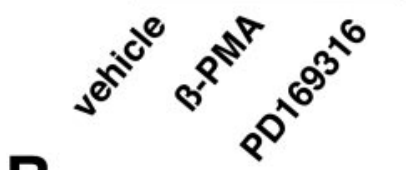

B

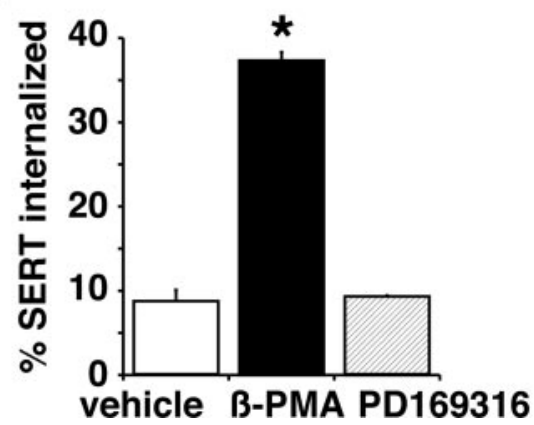

Figure 11. Effects of $\beta$-PMA and PD169316 on SERT internalization. HEK-293 cells transiently transfected with hSERT were surface biotinylated using cleavable biotin, incubated with vehicle, $\beta$-PMA $(1.0 \mu \mathrm{M})$, or PD169316 $(10 \mu \mathrm{M})$ for $30 \mathrm{~min}$ at $37^{\circ} \mathrm{C}$, washed, and stripped with cell-impermeant MesNa. Biotinylated SERTs were isolated with avidin, and internalized SERT was quantified after Western blot analysis (as described in Materials and Methods). A, Representative Western blots for total surface SERT before and after MesNa treatment $\left(4^{\circ} \mathrm{C}\right)$ and for the internalized SERT $\left(37^{\circ} \mathrm{C}\right) . B$, Quantification of internalized SERT. Data are expressed as a fraction of the total surface SERT internalized, and averaged data from three separate experiments are shown as the mean \pm SEM. Values significantly different from vehicle-treated cells $\left({ }^{*} p<0.01\right.$; one-way ANOVA with Bonferroni post hoc analysis).

that phosphorylates p38 MAPK, increased the level of phosphop38 MAPK and 5-HT transport and surface expression. Additionally, decreasing p38 MAPK expression by siRNAs reduced 5-HT transport and surface SERT expression, indicating that basal SERT activity might be maintained by constitutively active p38 MAPK.

The decrease in 5-HT uptake after PD169316 treatment was caused by a significant reduction in transport capacity and a moderate decrease in $K_{\mathrm{m}}$. The decrease in 5-HT uptake after $\beta$-PMA or PD169316 might be caused partially by release of 5-HT from synaptosomal preparations. Therefore, these values may represent an underestimate of 5-HT transport but are consistent with reduced surface SERT density and 5-HT uptake. After completion of the present experiments, Zhu et al. (2004) showed that short-term incubation of the p38 MAPK inhibitor SB203580 blocks an adenosine receptor $\left(\mathrm{AR}_{3}\right)$-mediated increase in 5-HT uptake in rat basophilic leukemia $2 \mathrm{H} 3$ cells and transfected Chinese hamster ovary cells with SERT and $\mathrm{AR}_{3}$, but SB203580 had no effect on an $\mathrm{AR}_{3}$-mediated increase in SERT surface expression. Our findings, however, indicate that p38 MAPK inhibition affects SERT insertion to the plasma membrane. The discrepancy with regard to the effect of p38 MAPK inhibition on SERT surface expression is not clear but may be related to time of treatment, cell type used, different isoforms of p38 MAPK expression between cell model systems used, expression level, and ratio of distribution of SERT in plasma membrane

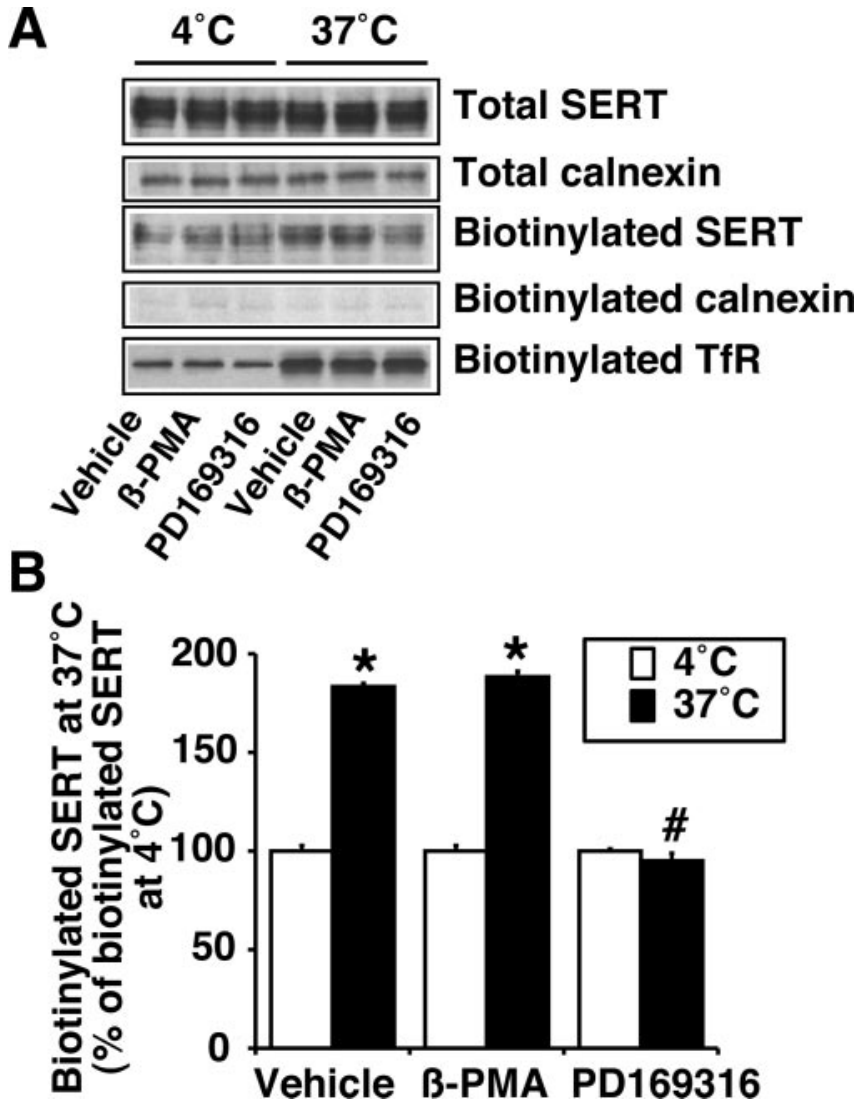

Figure 12. Effects of $\beta$-PMA and PD169316 on insertion of SERT to the plasma membrane. HEK-293 cells transiently transfected with hSERT were incubated with biotinylating reagent at $37^{\circ}$ or $4^{\circ} \mathrm{C}$ with or without $\beta$-PMA $(1.0 \mu \mathrm{M})$ or PD169316 $(10 \mu \mathrm{M})$ for $30 \mathrm{~min}$ (as described in Materials and Methods). $A$, Representative Western blots of SERT and calnexin from total lysate as well as Western blots of SERT, calnexin, and transferrin receptor from avidin bead eluates are shown. B, Quantitative analysis of SERT band densities. *Significant changes in biotinylated SERT at $37^{\circ} \mathrm{C}$ compared with biotinylated SERT at $4^{\circ} C_{\text {; }}{ }^{*}$ significant change compared with vehicle or $\beta$-PMA treatment at $37^{\circ} \mathrm{C}(p<0.05$; one-way ANOVA with Bonferroni post hoc analysis).

versus intracellular pool. The sensitivity of D-amphetaminemediated SERT phosphorylation to p38 MAPK inhibition indicates that p38 MAPK might target transport function of plasma membrane-inserted SERT. In agreement with the studies of Zhu et al. (2004), our results suggest that p38 MAPK may target SERT molecules at different levels in different cellular locations and that p38 MAPK-mediated SERT basal phosphorylation may impact SERT trafficking and catalytic activity. SERT contains consensus sites for PKC and other kinases, suggesting that alterations in SERT phosphorylation state may dictate transporter localization either to surface-microdomains or intracellular compartments (Ramamoorthy et al., 1993b; Vaughan, 2004). PKC activation induces phosphorylation of SERT and other monoamine transporters (Ramamoorthy, 2002; Vaughan, 2004). SERT is constitutively phosphorylated, and the basal phosphorylation of SERT is not affected by PKC, PKA, CaMK inhibitors, and $\mathrm{Ca}^{2+}$ chelation (Ramamoorthy et al., 1998a). The finding that inhibition of p38 MAPK decreases SERT basal phosphorylation suggests that constitutively active p38 MAPK is involved in maintaining SERT basal phosphorylation. Because activation of PKC or inhibition of p38 MAPK resulted in increased SERT internalization and reduced insertion, respectively, p38 MAPK and PKC must act on different phospho sites, if direct phosphorylation is involved in both processes. Activation of the MAPK pathway is 
both PKC dependent and independent. The present study demonstrates that SERT regulation by p38 MAPK is independent of PKC activation. Therefore, it is possible that phospho sites on SERT for p38 MAPK and PKC might be different and that p38 MAPK activation may be an important mechanism that constitutively regulates basal SERT expression and activity. Phosphorylation and hence MAPK activation downstream of a presynaptic receptor activation might be a possible signaling mechanism underlying p38 MAPK-mediated SERT regulation.

Phosphorylation studies indicated that p38 MAPK-dependent phosphorylation of SERT in synaptosomes may be involved in regulating the constitutive expression of SERT and that p38 MAPK may govern substrate (D-amphetamine)-mediated effects on SERT basal phosphorylation. Transporter substrates are known to regulate transporter function and expression (Bernstein and Quick, 1999; Duan et al., 1999; Ramamoorthy and Blakely, 1999; Munir et al., 2000; Chi and Reith, 2003). The present study demonstrates that a SERT substrate, D-amphetamine, increases SERT basal phosphorylation that is sensitive to 38 MAPK inhibition, suggesting that constitutively active p38 MAPK regulates SERT substrate effects on SERT phosphorylation; however, we cannot rule out a possible influence of monoamines released from synaptosomes by D-amphetamine on SERT basal phosphorylation. Although not tested in the present study, it is possible that substrates may influence SERT surface expression by regulating p38 MAPKmediated transporter phosphorylation.

The data presented in this study are similar with respect to SERT interaction with PP2Ac or syntaxin 1A after PKC activation (Bauman et al., 2000; Haase et al., 2001; Quick, 2002, 2003). Our findings that PD169316 inhibits SERT-syntaxin 1A association as well as decreases SERT insertion to the plasma membrane suggest that p38 MAPK might regulate SERT insertion, possibly by regulating dynamic SERT-syntaxin 1A interactions; however, whether SERT basal phosphorylation is involved in this regulation remains to be seen. Because our data suggest that PD169316 reduces SERT-PP2Ac association and 5-HT transport, it is reasonable to speculate that the SERT-associated PP2Ac may regulate the stability of phospho-SERT by regulating dephosphorylation of phospho-SERT. SERT-associated PP2Ac may also dephosphorylate SERT-associated proteins and thus regulate the functional role of SERT-associated proteins in SERT regulation. Syntaxin 1A has been shown to be phosphorylated by different protein kinases, and phosphorylation of syntaxin $1 \mathrm{~A}$ regulates its interaction with other proteins (Foletti et al., 2000; Tian et al., 2003). p38 MAPK regulates the activity and translocation of PP2Ac (Liu and Hofmann, 2004). Thus, phosphatase activity from the SERT-P2Ac complex may participate at different levels, maintaining appropriate levels of functional SERTs to coordinate with various cellular stimuli. Nonetheless, the demonstration that p38 MAPK regulates not only SERT function and expression but also its association with PP2Ac and syntaxin 1A suggests that $\mathrm{p} 38$ MAPKs may contribute to the regulation of serotonin signaling and synaptic strength via regulation of protein-protein interactions.

Protein redistribution from plasma membrane microdomains may be one of the several mechanisms by which synaptic plasticity and neurotransmitter homeostasis are maintained ( $\mathrm{Si}$ mons and Ikonen, 1997; Parton and Hancock, 2004). Membrane cholesterol modulates SERT activity in HEK-293 cells, although cholesterol appears to be involved in stabilizing transporter proteins and not in trafficking regulation (Scanlon et al., 2001). The present study demonstrates that SERT is localized in lipid rafts and raft-associated SERT moves to nonlipid raft fractions after PKC stimulation but not p38 MAPK inhibition. Raft-mediated internalization has been demonstrated in the regulation of glucose and norepinephrine transporters (Ros-Baro et al., 2001; Jayanthi et al., 2004). After completion of the present experiments, the role of lipid raft localization in the PKA-mediated regulation of excitatory amino acid transporters and the localization of SERT in lipid rafts was reported (Butchbach et al., 2004; Magnani et al., 2004). Raft-associated sorting has been proposed to underlie several cellular processes, including signal transduction, protein sorting, and membrane trafficking (Chamberlain et al., 2001). SERT distribution in lipid and nonlipid raft fractions suggests that the spatial segregation of SERT and signaling components in lipid rafts can be accounted for by distinct mechanisms of regulation by different protein kinases involving transporter phosphorylation, trafficking, and interaction with other proteins. It is therefore possible that SERT may be localized in discrete pools within the plasma membrane and that PKC, but not $\mathrm{p} 38$ MAPK, targets a SERT pool that is present only in the rafts and triggers transporter internalization.

The molecular mechanisms underlying the differences in PKC- and p38 MAPK-mediated SERT regulation are of considerable biological importance, because regulation of SERT in response to different kinases-phosphatases may be linked to specific presynaptic receptor activation in serotonergic terminals. The differential effects of PKC and p38 MAPK suggest the involvement of multiple signaling pathways acting at multiple levels of SERT regulation in maintaining 5-HT homeostasis and normal serotonergic neurotransmission. Any perturbation in this homeostasis might lead to an altered 5-HT signaling. Numerous studies have indicated altered extracellular 5-HT, 5-HT synthesis-metabolism, 5-HT receptor signaling cascades, SERT binding sites, and serotonergic neuronal firing in response to numerous stressors (Chaouloff et al., 1999). Thus, adjustments in 5-HT neurotransmission might allow an appropriate behavioral response to stress. The regulation of SERT by $\mathrm{p} 38 \mathrm{MAPK}$, a stressinduced kinase, may provide a novel presynaptic mechanism in maintaining appropriate synaptic 5-HT levels during stressful conditions.

\section{References}

Ansah TA, Ramamoorthy S, Montanez S, Daws LC, Blakely RD (2003) Calcium-dependent inhibition of synaptosomal serotonin transport by the alpha 2-adrenoceptor agonist 5-bromo- $N$-[4,5-dihydro- $1 \mathrm{H}$ imidazol-2-yl]-6-quinoxalinamine (UK14304). J Pharmacol Exp Ther 305:956-965.

Armando I, Tjurmina OA, Li Q, Murphy DL, Saavedra JM (2003) The serotonin transporter is required for stress-evoked increases in adrenal catecholamine synthesis and angiotensin II AT(2) receptor expression. Neuroendocrinology 78:217-225.

Barker EL, Blakely RD (1995) Norepinephrine and serotonin transporters: molecular targets of antidepressant drugs. In: Psychopharmacology: the fourth generation of progress (Bloom FE, Kupfer DJ, eds), pp 321-333. New York: Raven.

Bauman AL, Apparsundaram S, Ramamoorthy S, Wadzinski BE, Vaughan RA, Blakely RD (2000) Cocaine and antidepressant-sensitive biogenic amine transporters exist in regulated complexes with protein phosphatase 2A. J Neurosci 20:7571-7578.

Becher A, White JH, McIlhinney RA (2001) The gamma-aminobutyric acid receptor $\mathrm{B}$, but not the metabotropic glutamate receptor type-1, associates with lipid rafts in the rat cerebellum. J Neurochem 79:787-795.

Benmansour S, Cecchi M, Morilak DA, Gerhardt GA, Javors MA, Gould GG, Frazer A (1999) Effects of chronic antidepressant treatments on serotonin transporter function, density, and mRNA level. J Neurosci 19:10494-10501.

Bernstein EM, Quick MW (1999) Regulation of gamma-aminobutyric acid (GABA) transporters by extracellular GABA. J Biol Chem 274:889-895.

Blakely RD, Ramamoorthy S, Qian Y, Schroeter S, Bradley C (1997) Regulation of antidepressant-sensitive serotonin transporters. In: Neurotrans- 
mitter transporters: structure, function, and regulation (Reith MEA, ed), pp 29-72. Totowa, NJ: Humana.

Butchbach ME, Tian G, Guo H, Lin CL (2004) Association of excitatory amino acid transporters, especially EAAT2, with cholesterol-rich lipid raft microdomains: importance for excitatory amino acid transporter localization and function. J Biol Chem 279:34388-34396.

Chamberlain LH, Burgoyne RD, Gould GW (2001) SNARE proteins are highly enriched in lipid rafts in PC12 cells: implications for the spatial control of exocytosis. Proc Natl Acad Sci USA 98:5619-5624.

Chaouloff F, Berton O, Mormede P (1999) Serotonin and stress. Neuropsychopharmacology 21[Suppl 1]:S28-S32.

Chi L, Reith ME (2003) Substrate-induced trafficking of the dopamine transporter in heterologously expressing cells and in rat striatal synaptosomal preparations. J Pharmacol Exp Ther 307:729-736.

Duan S, Anderson CM, Stein BA, Swanson RA (1999) Glutamate induces rapid upregulation of astrocyte glutamate transport and cell-surface expression of GLAST. J Neurosci 19:10193-10200.

Eichberg J, Whittaker VP, Dawson RM (1964) Distribution of lipids in subcellular particles of guinea-pig brain. Biochem J 92:91-100.

Foletti DL, Lin R, Finley MA, Scheller RH (2000) Phosphorylated syntaxin 1 is localized to discrete domains along a subset of axons. J Neurosci 20:4535-4544.

Fournier KM, Gonzalez MI, Robinson MB (2004) Rapid trafficking of the neuronal glutamate transporter, EAAC1: evidence for distinct trafficking pathways differentially regulated by protein kinase $\mathrm{C}$ and platelet-derived growth factor. J Biol Chem 279:34505-34513.

Fozzard J (1989) Peripheral actions of 5-hydroxytryptamine. New York: Oxford UP.

Geerlings A, Nunez E, Lopez-Corcuera B, Aragon C (2001) Calcium- and syntaxin 1-mediated trafficking of the neuronal glycine transporter GLYT2. J Biol Chem 276:17584-17590.

Haase J, Killian AM, Magnani F, Williams C (2001) Regulation of the serotonin transporter by interacting proteins. Biochem Soc Trans 29:722-728.

Jacobs B, Azmitia EC (1992) Structure and function of the brain serotonin system. Physiol Rev 72:165-229.

Jayanthi LD, Ramamoorthy S, Mahesh VB, Leibach FH, Ganapathy V (1994) Calmodulin-dependent regulation of the catalytic function of the human serotonin transporter in placental choriocarcinoma cells. J Biol Chem 269:14424-14429.

Jayanthi LD, Samuvel DJ, Ramamoorthy S (2004) Regulated internalization and phosphorylation of the native norepinephrine transporter in response to phorbol esters: evidence for localization in lipid rafts and lipid raft-mediated internalization. J Biol Chem 279:19315-19326.

Lesch KP, Aulakh CS, Wolozin BL, Tolliver TJ, Hill JL, Murphy DL (1993) Regional brain expression of serotonin transporter mRNA and its regulation by reuptake inhibiting antidepressants. Brain Res Mol Brain Res 17:31-35.

Lin Z, Zhang PW, Zhu X, Melgari JM, Huff R, Spieldoch RL, Uhl GR (2003) Phosphatidylinositol 3-kinase, protein kinase $\mathrm{C}$, and MEK1/2 kinase regulation of dopamine transporters (DAT) require N-terminal DAT phosphoacceptor sites. J Biol Chem 278:20162-20170.

Liu Q, Hofmann PA (2004) Protein phosphatase 2A-mediated cross-talk between p38 MAPK and ERK in apoptosis of cardiac myocytes. Am J Physiol Heart Circ Physiol 286:H2204-H2212.

Loder MK, Melikian HE (2003) The dopamine transporter constitutively internalizes and recycles in a protein kinase C-regulated manner in stably transfected PC12 cell lines. J Biol Chem 278:22168-22174.

Magnani F, Tate CG, Wynne S, Williams CD, Haase J (2004) Partitioning of the serotonin transporter into lipid microdomains modulates transport of serotonin. J Biol Chem 279:38770-38778.

McDuffie JE, Motley ED, Limbird LE, Maleque MA (2000) 5-Hydroxytryptamine stimulates phosphorylation of $\mathrm{p} 44 / \mathrm{p} 42$ mitogen-activated protein kinase activation in bovine aortic endothelial cell cultures. J Cardiovasc Pharmacol 35:398-402.

Miller KJ, Hoffman BJ (1994) Adenosine $A_{3}$ receptors regulate serotonin transport via nitric oxide and cGMP. J Biol Chem 269:27351-27356.

Montgomery SA (1995) Selective serotonin reuptake inhibitors in the acute treatment of depression. In: Psychopharmacology: the fourth generation (Bloom FE, Kupfer DJ, eds), pp 1043-1051. New York: Raven.

Morikawa O, Sakai N, Obara H, Saito N (1998) Effects of interferon-alpha, interferon-gamma and cAMP on the transcriptional regulation of the serotonin transporter. Eur J Pharmacol 349:317-324.
Moron JA, Zakharova I, Ferrer JV, Merrill GA, Hope B, Lafer EM, Lin ZC, Wang JB, Javitch JA, Galli A, Shippenberg TS (2003) Mitogen-activated protein kinase regulates dopamine transporter surface expression and dopamine transport capacity. J Neurosci 23:8480-8488.

Mossner R, Daniel S, Schmitt A, Albert D, Lesch KP (2001) Modulation of serotonin transporter function by interleukin-4. Life Sci 68:873-880.

Munir M, Correale DM, Robinson MB (2000) Substrate-induced upregulation of $\mathrm{Na}(+)$-dependent glutamate transport activity. Neurochem Int 37:147-162.

Murphy DL, Li Q, Engel S, Wichems C, Andrews A, Lesch KP, Uhl G (2001) Genetic perspectives on the serotonin transporter. Brain Res Bull 56:487-494.

Neumaier JF, Root DC, Hamblin MW (1996) Chronic fluoxetine reduces serotonin transporter mRNA and 5-HT1B mRNA in a sequential manner in the rat dorsal raphe nucleus. Neuropsychopharmacology 15:515-522.

Parton RG, Hancock JF (2004) Lipid rafts and plasma membrane microorganization: insights from Ras. Trends Cell Biol 14:141-147.

Povlock SL, Amara SG (1997) The structure and function of norepinephrine, dopamine, and serotonin transporters. In: Neurotransmitter transporters: structure, function, and regulation (Reith MEA, ed), pp 1-28. Totowa, NJ: Humana.

Qian Y, Galli A, Ramamoorthy S, Risso S, DeFelice LJ, Blakely RD (1997) Protein kinase $\mathrm{C}$ activation regulates human serotonin transporters in HEK-293 cells via altered cell surface expression. J Neurosci 17:45-47.

Quick MW (2002) Role of syntaxin 1A on serotonin transporter expression in developing thalamocortical neurons. Int J Dev Neurosci 20:219-224.

Quick MW (2003) Regulating the conducting states of a mammalian serotonin transporter. Neuron 40:537-549.

Ramamoorthy S (2002) Regulation of monoamine transporters: regulated phosphorylation, dephosphorylation and trafficking. In: neurotransmitter transporter: structure, function and regulation (Reith MEA, ed), pp 1-23. Totowa, NJ: Humana.

Ramamoorthy S, Blakely RD (1999) Phosphorylation and sequestration of serotonin transporters differentially modulated by psychostimulants. Science 285:763-766.

Ramamoorthy S, Cool DR, Mahesh VB, Leibach FH, Melikian H, Blakely RD, Ganapathy V (1993a) Regulation of the human serotonin transporter: cholera toxin-induced stimulation of serotonin uptake in human placental choriocarcinoma cells is accompanied by increased serotonin transporter mRNA levels and serotonin transporter-specific ligand binding. J Biol Chem 268:21626-21631.

Ramamoorthy S, Bauman AL, Moore KR, Han H, Yang-Feng T, Chang AS, Ganapathy V, Blakely RD (1993b) Antidepressant- and cocainesensitive human serotonin transporter: molecular cloning, expression, and chromosomal localization. Proc Natl Acad Sci USA 90:2542-2546.

Ramamoorthy JD, Ramamoorthy S, Papapetropoulos A, Catravas JD, Leibach FH, Ganapathy V (1995a) Cyclic AMP-independent upregulation of the human serotonin transporter by staurosporine in choriocarcinoma cells. J Biol Chem 270:17189-17195.

Ramamoorthy S, Ramamoorthy JD, Prasad P, Bhat GK, Mahesh VB, Leibach FH, Ganapathy V (1995b) Regulation of the human serotonin transporter by interleukin-1 $\beta$. Biochem Biophys Res Commun 216:560-567.

Ramamoorthy S, Giovanetti E, Qian Y, Blakely RD (1998a) Phosphorylation and regulation of antidepressant-sensitive serotonin transporters. J Biol Chem 273:2458-2466.

Ramamoorthy S, Melikian HE, Qian Y, Blakely RD (1998b) Biosynthesis, $\mathrm{N}$-glycosylation, and surface trafficking of biogenic amine transporter proteins. Methods Enzymol 296:347-370.

Ros-Baro A, Lopez-Iglesias C, Peiro S, Bellido D, Palacin M, Zorzano A, Camps M (2001) Lipid rafts are required for GLUT4 internalization in adipose cells. Proc Natl Acad Sci USA 98:12050-12055.

Rudnick G, Wall SC (1992) The molecular mechanism of "ecstasy" [3,4methylenedioxymethamphetamine (MDMA)]: serotonin transporters are targets for MDMA-induced serotonin release. Proc Natl Acad Sci USA 89:1817-1821.

Scanlon SM, Williams DC, Schloss P (2001) Membrane cholesterol modulates serotonin transporter activity. Biochemistry 40:10507-10513. 
Schramm NL, Limbird LE (1999) Stimulation of mitogen-activated protein kinase by $\mathrm{G}$ protein-coupled alpha(2)-adrenergic receptors does not require agonist-elicited endocytosis. J Biol Chem 274:24935-24940.

Simons K, Ikonen E (1997) Functional rafts in cell membranes. Nature 387:569-572.

Tian JH, Das S, Sheng ZH (2003) $\mathrm{Ca}^{2+}$-dependent phosphorylation of syntaxin-1A by the death-associated protein (DAP) kinase regulates its interaction with Munc18. J Biol Chem 278:26265-26274.

Tibbles LA, Woodgett JR (1999) The stress-activated protein kinase pathways. Cell Mol Life Sci 55:1230-1254.

Treisman R (1996) Regulation of transcription by MAP kinase cascades. Curr Opin Cell Biol 8:205-215.
Vaughan RA (2004) Phosphorylation and regulation of psychostimulantsensitive neurotransmitter transporters. J Pharmacol Exp Ther 310:1-7.

Vaughan RA, Huff RA, Uhl GR, Kuhar MJ (1997) Protein kinase C-mediated phosphorylation and functional regulation of dopamine transporters in striatal synaptosomes. J Biol Chem 272:15541-15546.

Vollmayr B, Keck S, Henn FA, Schloss P (2000) Acute stress decreases serotonin transporter mRNA in the raphe pontis but not in other raphe nuclei of the rat. Neurosci Lett 290:109-112.

Zhu CB, Hewlett WA, Feoktistov I, Biaggioni I, Blakely RD (2004) Adenosine receptor, protein kinase $\mathrm{G}$, and $\mathrm{p} 38$ mitogen-activated protein kinase-dependent up-regulation of serotonin transporters involves both transporter trafficking and activation. Mol Pharmacol 65:1462-1474. 